\title{
Supplier Selection Behavior under Uncertainty: Contextual and Cognitive Effects on Risk Perception and Choice
}

Earlier version of a paper published under the following reference

Kull T.J., Oke A., \& Dooley K. "Supplier Selection Decision Behavior under Uncertainty: Contextual and Cognitive Effects on Risk Perception and Choice," Decision Sciences, 45 (3), 2014

Thomas J. Kull†, Adegoke Oke, and Kevin J. Dooley

$\dagger$ Corresponding

Department of Supply Chain Management, WP Carey School of Business, Arizona State University, Tempe, AZ 85287-4706

e-mail: Thomas.Kull@asu.edu, Adegoke.Oke@asu.edu, Kevin.Dooley@asu.edu 


\title{
Supplier Selection Behavior under Uncertainty: Contextual and Cognitive Effects on Risk Perception and Choice
}

\begin{abstract}
Buyers often make supplier selection decisions under conditions of uncertainty. While the analytical aspects of supplier selection are well developed, the psychological aspects are less so. This paper uses literature from supply chain management and behavioral decision theory to propose the following: While attributes of a purchase category (i.e., category difficulty, category importance, and contingent pay) influence risk perceptions, cognitive processes exist that additionally influence risk perceptions and affect a supply manager's choice. We conducted a supplier selection behavioral experiment with practicing managers to test the model's hypotheses. When the context involves an important or difficult sourcing category, higher risk perceptions exist that increase preferences for a supplier with more certain outcomes, even when that decision has a lower expected payoff. However, the presence of contingent pay decreases risk perceptions through higher perceived supplier control. Also, we find that a manager's risk propensity increases preferences for a supplier with less certain outcomes regardless of perceived risk. Our model and results provide a theoretical framework for further study into the cognitive aspects of supplier selection behavior and provides insight into decisional biases that practicing supply chain managers may be subject to.
\end{abstract}

\section{INTRODUCTION}

Supplier selections have become important due to the increasing strategic role that suppliers play in a buying firm's competitive landscape (Narasimhan \& Talluri, 2009). Because supply managers in principal-agent situations make strategic supplier selections with long-term 
consequences (Weber, Current, \& Benton, 1991), researchers have examined how to mitigate the negative consequences of risk-related supply decisions (Chopra \& Sodhi, 2004; Craighead, Blackhurst, Rungtusanatham, \& Handfield, 2007). However, less is known about the cognitive antecedents to such decisions. Supplier selection is a decision with inherent uncertainty (Hult, Craighead, \& Ketchen, 2010), with managers assessing each supplier's risks and capabilities in meeting the buying firm's sourcing objectives (Treleven \& Schweikhart, 1988; Tomlin, 2006). Yet, such assessments rely on the perceptions and judgments of managers that are susceptible to contextual and cognitive biases (Amaral \& Tsay, 2009; Ellis, Henry, \& Shockley, 2010). In this study, we focus on specific contextual and cognitive processes that influence supplier selection behavior under uncertainty, i.e., with variance in potential outcomes (Ghosh \& Crain, 1993).

Theories and models concerning supplier selection have been developed from a rational decision-making perspective to prescribe choices under various supply conditions (Choi \& Hartley, 1996; McCutcheon \& Stuart, 2000; Narasimhan, Talluri, \& Mahapatra, 2006). More study is needed, however, into how supply conditions affect cognitive processes and thus supply management decisions (Mitchell, 1995). We investigate how contextual factors commonly experienced by supply managers, such as a purchased component's strategic importance, its sourcing difficulty, and a manager's compensation scheme influence risk perception and the subsequent effect on supplier selection (Olsen \& Ellram, 1997; Villena, Gomez-Mejia, \& Revilla, 2009). While some behavioral operations work has been done in this area (Ellis et al., 2010), supply chain research has yet to examine how supplier selection is influenced by individual biases toward risk and control (Langer, 1975; March \& Shapira, 1987; Sitkin \& Pablo, 1992). To understand the behavioral antecedents of supplier selection involving 
uncertainty, we draw from behavioral decision theory to develop hypotheses for how sourcing context characteristics and managerial cognitive biases impact decision outcomes.

The first major objective of this study is to test a cognitive model of determinants of a supplier selection behavior under uncertainty. Studies in behavioral decision theory have illuminated various factors that relate to decision-making behavior under uncertainty: examples include the effect of ambiguity (Fox \& Tversky, 1995), effects of time (Busemeyer \& Townsend, 1993), framing effects (Levin, Schneider, \& Gaeth, 1998), compensation effects (Wiseman \& Gomez-Mejia, 1998), risk propensity and risk perceptions effects (Slovic, 1987; Sitkin \& Pablo, 1992), and post-decisional control effects (Shapira, 1995; Harvey \& Victoravich, 2009) on decision-making behavior. While behavioral operations literature has examined how subsets of these factors influence decisions (Keil, Depledge, \& Rai, 2007; Ellis et al., 2010; Bendoly, 2013), we are not aware of any study within the operations or supply chain management fields that has examined how both contextual and cognitive factors affect risk perceptions and subsequent supplier selection behavior. Moreover, few supply chain studies incorporate the influence of perceptions of control on decision-making behavior (see Davis \& Kottemann, 1994; Hunton, 1996; Bendoly, Thomas, \& Capra, 2010b). This paper contributes by proposing a model incorporating these concepts and testing it with managers in a controlled experiment.

The second major objective of this study is to extend research challenging the assumption that supply managers act as agents of a firm without personal biases or preferences affecting their decisions (Carter, Kaufmann, \& Michel, 2007). While norms emanating from institutional and academic sources emphasize that supply chain managers base decisions on firm-specific objectives and criteria (Monczka, Handfield, Giunipero, \& Patterson, 2009), behavioral decision theory emphasizes that perceptions and judgments are unavoidably biased (Gino \& Pisano, 
2008). Our study contributes by eliciting the influence of cognitive factors on supplier selection decisions under uncertainty, thus contributing to a growing body of literature that highlights the importance of behavioral issues in operations and supply chain management (Bendoly, Croson, Goncalves, \& Schultz, 2010a; Bendoly \& Eckerd, 2013).

The paper is structured as follows. First, we present the constructs in our model and hypothesize their interrelationships. Next, we discuss the methodology, including the experimental design, execution, and validity. We then present our model-testing approach and results. Finally, we discuss the results and conclude with theoretical and managerial implications and identify potential future research opportunities.

\section{THEORETICAL BACKGROUND AND HYPOTHESES}

Complex cognitive processes are involved when a decision-maker is operating under conditions of high uncertainty. Environmental and organizational contexts interact with individual perceptions, as well as motivations for achievement and security, to influence the decision (Webster \& Wind, 1972; Mitchell, 1995; Conchar, Zinkhan, Peters, \& Olavarrieta, 2004). Our study uses known determinants of risk-taking behavior (see Sitkin \& Pablo, 1992; Sitkin \& Weingart, 1995) to develop a seven-construct model as shown in Figure 1. Construct definitions and references are provided in Table 1. In brief, we propose that sourcing category (i.e. sourcing category difficulty and importance) and personal incentives (contingent pay) influence a manager's perceptions of risk and of supplier control, which along with the manager's a priori risk propensity have effects on their selection risk taking. 
Literature commonly assumes that the decision maker is a rational economic agent when selecting a supplier: they have knowledge of the supplier selection problem, they can create clear firm-based preferences amongst the choices of suppliers, they have the skills necessary to determine which supplier choice is optimal, and they are indifferent to difference supplier choice sets that are equivalent except for the way they are described (Rubinstein, 1998). There are several arguments to support this assumption. First, supplier selection is an organizational-level decision made by one or more individuals acting as agents for the organization (Eisenhardt, 1989). Second, because decision-makers are aware that negative consequences from their decision may be attributed to them, they are likely to engage in a rational manner (i.e., using all available information and being as objective as possible) to ensure that their decision process is auditable (March \& Shapira, 1987). Third, a supplier selection decision, which often occurs when an existing supplier does not exist, involves a decision-maker that has not previously interacted with the suppliers considered. Thus, emotional influences should be low so that the decision will be made rationally. Finally, application of the "Dutch Book" argument (Rubinstein, 2012) to the supplier selection context would propose that an economic agent who does not act in a rational manner will make repeatedly poor decisions and their decisional authority will not survive.

In reality, however, decision makers have bounded rationality, being affected by such causes as recency and primacy, framing, information processing limitations, and bias (Gino \& Pisano, 2008). Acknowledging this reality has moved decision theory to more explanatory and 
useful models of decision making. Likewise, behavioral operations and supply management literature has advanced our understanding of operational decisions substantially with the incorporation of behavioral and bounded rational factors (Tiwana, Wang, Keil, \& Ahluwalia, 2007; Croson, Schultz, Siemsen, \& Yeo, 2013). In our model, we explore two possible sources of bounded rationality. First, contingent pay, which creates personal incentives linked to the consequence of the decision, is posited to bias perceptions of control that impact rationality. Second, risk propensity, which is an individual attribute of the decision-maker that exists prior to the decision, is posited to bias supplier choice because supply managers will emphasize benefits and losses differently.

From a rational economic agent perspective, supply managers will determine the optimal supplier choice by calculating the expected value of the different choice options (Narasimhan et al., 2006). Expected value can be expressed as a function of two factors - the probability of a particular outcome, and the magnitude of the outcome, or decision consequence (Schoemaker, 1982). For example, if a supplier selection problem was based purely on cost, and supplier A had a 50 percent chance of reducing cost per unit by $\$ 10$, while supplier B had a 25 percent chance of reducing cost per unit by $\$ 50$, then a supply manager would choose supplier B because the expected reduction in cost per unit is greater for supplier $B(0.25 \times \$ 50=\$ 12.50)$ than for supplier A $(0.50 \times \$ 10=\$ 5.00)$. Risk is similarly conceptualized as the probability and magnitude of loss (Yates \& Stone, 1992), and supply management models have commonly used this formulation to describe how decision-makers perceive risk and behave (Ellis et al., 2010; Ho, Xu, \& Dey, 2010).

We define the decision-maker's risk perception as the overall assessment of the probabilities and magnitudes of potential losses associated with a supplier selection situation. 
Sitkin and Pablo (1992) argue that risk perception is an underlying mechanism crucial to understanding decision-making behavior under uncertainty. That is, the level of risk perceived in a situation strongly determines risk behavior. Numerous managerial studies have found risk perception to be an important determinant of behavior (Pennings \& Wansink, 2004; Klos, 2005; Forlani, Parthasarathy, \& Keaveney, 2008). We propose that sourcing category, contingent pay, perceived supplier control, and risk propensity influence risk perceptions in a supplier selection problem.

\section{Sourcing Categories and Risk Perceptions}

The strategic sourcing of suppliers can involve significant uncertainty and consequences. Strategic sourcing often begins with classifying the component into a category based on its difficulty and importance (Kraljic, 1983; Olsen \& Ellram, 1997) before determining what suppliers to select and what supplier strategies to use (Goldfeld, 1999; Monczka et al., 2009). Sourcing category importance and sourcing category difficulty are the bases for the popular classification of sourcing components by Kraljic (1983) into four categories: routine (low difficulty and low importance), bottleneck (high difficulty and low importance), leverage (low difficulty and high importance), and strategic (high difficulty and high importance). Because a supply strategy depends on the difficulty of the supply market and the strategic importance of the purchased product, the purchase category can frame the context for subsequent decisions.

Our first hypothesis pertains to the difficulty of a sourcing category, which is influenced by characteristics of the component (i.e., product novelty and complexity), the supply market (e.g., suppliers' power), and the environment (e.g., turbulence) (Olsen \& Ellram, 1997). From a buying firm's perspective, the novelty and the complexity of a sourcing category creates a 
problematic sourcing context because of the uncertainties involved - e.g., uncertainties for manufacturability and for final product effects (Monczka et al., 2009). Similarly, high supplier power increases the dependency on the supplier for the purchase category (Crook \& Combs, 2007), raising the likelihood of scheduling problems and high switching costs for the buyer (Goldfeld, 1999). If a purchase category has low difficulty, it is relatively easy for supply managers to implement contingencies to decrease the impact of a potential supplier failure for that category. For example, changing to a different supplier or finding a temporary supplier are contingency strategies that can be easily executed for a purchase category with low difficulty. However, if a sourcing category has high difficulty, these contingencies may not be easy or even feasible, hence increasing supply managers' perception of risk in the situation. In other words, sourcing for categories with high difficulty increase the perceived probability that problems will arise regardless of the supplier selected. Ellis et al. (2010) find that a component's technological uncertainty and the thinness of the related supply market increase the perceived risk of component currently being supplied; in part because of an increased perception that disruptions are likely under these conditions. Thus,

H1: Sourcing category difficulty is positively associated with perceived risk.

In a supply context, the importance of a sourcing category represents strategic factors (i.e., the extent to which the purchase is part of the firm's core competence) and economic factors (i.e., percentage of the purchase in total costs) (Olsen and Ellram, 1997). Important purchases typically have strong influences on company results and are critical to the business (Kraljic, 1983; Goldfeld, 1999). While important purchases present opportunities for greater rewards if there is a successful follow-through on such contracts, important purchases with 
uncertain outcomes can have substantial consequences and can be associated with high risk (Bettman, 1973). In a supplier selection under uncertainty, if a sourcing category has low importance, then supply managers perceive the consequence, and thus risk, as lower because either slack exists in the need for the supply, or failures will not be as visible or impactful in the organization. Conversely, if a sourcing category is of high importance, then the consequence of a failure, and thus the risk, will be perceived as higher because a supply failure will impact a critical organizational need and, thus, be visible to many in the organization (Ellis et al. 2010). For example, when considering suppliers for a component that represents a large portion of product cost, uncertainty over future component prices could impact product margins. Thus, the supply manager making supplier selection might view or perceive this situation as threatening. Thus,

H2: Sourcing category importance is positively associated with perceived risk.

\section{Effects of Contingent Pay}

Managers select suppliers on behalf of their company; they are agents taking risks for the firm while being compensated and governed by the firm. Because governance structures alone do not adequately predict decision making under uncertainty (Catanach \& Brody, 1993), the behavioral agency model (BAM) was introduced to help "improve the predictive and explanatory value of agency-based models of executive risk-taking behavior" (Wiseman \& Gomez-Mejia, 1998,

p.135). Compensation schemes tightly couple firm performance to agent consequences (Beatty \& Zajac, 1994). In BAM, much depends on the make-up of base and contingent pay. Base pay is the component of the total pay that is relatively more certain and more expected than contingent pay, which is more variable (Wiseman \& Gomez-Mejia, 1998). BAM has recently been applied 
to supply chain decision-making, where Villena et al. (2009) find that compensation schemes that increase threats to expected supply chain executive wealth reduce the willingness to make risky decisions. We extend this work to a supplier selection context.

It is not uncommon for supply managers to have a contingent pay compensation scheme (Rossetti \& Choi, 2005). Contingent pay in supply management typically relates to an incentive to improve a purchased part variance (PPV) metric. PPV exists when components are procured for an amount different than expected (Monczka et al., 2009). When supply managers succeed in securing supply sources below expected component costs, a favorable PPV occurs, saving the company money. One approach, therefore, to provide supply managers with contingent pay is to introduce compensation schemes that allocate bonuses for such cost savings. When such contingent pay does not exist, the supply manager will perceive that a positive outcome will not be rewarded, at least not immediately, and a negative outcome may lead to actions that threaten their base pay, which is their source of economic security. Thus, supply managers making a supplier selection under uncertainty will perceive risk as being relatively higher than a purely rational assessment would suggest. Conversely, when contingent pay exists and is relatively high, the supply manager may perceive less of a threat to their expected wealth because the presence, or lack thereof, of the contingent pay does not impact their base salary. Therefore, based on the processes described in BAM we state the following hypothesis:

H3: A higher proportion of contingent pay is associated with lower perceived risk.

It is important to note that in formulating risk perceptions, decision-makers consider their ability to mitigate the consequences associated with a risk event after is has occurred. For example, in determining the consequences of going outside on a possibly rainy day, a person will 
discount the negative effects of the rain on them if they know they can carry an umbrella. According to the Theory of Planned Behavior (Ajze, 1991), perceived behavioral control (i.e. self-efficacy) positively affects the intent to act and action itself. As perceived behavioral control increases, an actor will be more likely to believe they have the skills and resources to succeed in their intended action. In the case of supplier selection, the intended action is to deliver positive benefits and avoid negative consequences associated with sourcing from a particular supplier, and part of the intended action is to mitigate the impact of risk events after the supplier selection decision has been made. Research confirms that illusions of controlling the consequences of a decision have a strong impact on the decision-maker's evaluation of those consequences (McKenna, 1993).

Shapira (1995) extended this concept to managerial decision making by describing how managers see themselves as actively influencing the uncertain outcomes associated with a decision. Managers often perceive risk taking not as a one-point-in-time decision, but rather as a process-over-time: If things go wrong they can change the course of action in order to remedy problems after the decision has been made. Managerial illusions of control can lead to inappropriately high expectancies of personal success (Langer, 1975) and can be induced through offering choices, reordering outcomes, familiarizing tasks, providing information, and offering feigned involvement (Presson \& Benassi, 1996). Shapira (1995) calls this the belief in post-decisional control, where a manager perceives an ability to influence the uncertain outcomes of a decision. Indeed, Bendoly et al. (2010b) found evidence for the argument that perceptions of control in projects increased the value that a manager places on social interactions because of a tendency to see more opportunities in those interactions. In our study, perceived supplier control relates to the supply managers' beliefs in their abilities to influence 
the consequences of an initial supplier selection - such as obtaining rush orders during supply disruptions or negotiating supplier concessions if costs increase.

Our model contributes by integrating BAM with perceptions of post-decisional control and risk (March \& Shapira, 1987). Dunford et al. (2010) recently find that contingent pay (i.e., offering stock options) positively influences perception of control (i.e., the expectancy that effort will influence stock performance), regardless of one's ability to control the situation. This implies that Shapira's (1995) post-decisional control concept can be integrated with BAM. That is, a high proportion of contingent pay will increase perceptions of control because of the impression given that outcomes can be influenced. Unlike base pay, contingent pay is more dependent on the decision maker's efforts (Wiseman \& Gomez-Mejia, 1998), thus giving a sense of control.

H4: A high proportion of contingent pay increases perceived supplier control.

\section{Influences on Perceived risk in Supplier Selection}

Sitkin and Pablo (1992) argue that risk perception is an underlying mechanism crucial to understanding decision-making behavior under uncertainty. That is, the level of risk perceived in a situation strongly determines risk behavior. Numerous managerial studies have found risk perception to be an important determinant of behavior (Pennings \& Wansink, 2004; Klos, 2005;

Forlani et al., 2008). We propose two constructs in our integrated model that influence risk perceptions in a supplier selection situation: perceived supplier control and risk propensity.

Risk involves an uncertainty as to whether unfavorable outcomes will occur (Yates \& Stone, 1992). In a supplier selection situation, however, these unfavorable outcomes are not immediate. Unexpected disruptions or quality failures can happen many months into the 
relationship. Thus, supply managers with strong beliefs that future events can be manipulated will not see potential negative consequences as likely to occur in supplier selection (Keil et al., 2007). This is because of their belief that if things go awry, they can enact whatever influence they have within the decision context and avoid future problems (March \& Shapira, 1987). For example, if there are warning signs relating to a potential supplier's ability to meet delivery times, supply managers' beliefs that this situation can be easily handled if it does occur will not preclude the supplier from being considered or even selected. In other words, the supply manager's perceived control over the situation will downplay the potential risks associated with a supplier's failure to meet delivery times, thus, perceiving that unfavorable outcomes are less likely (Sitkin \& Weingart, 1995). Accordingly, we offer the following hypothesis:

H5: Perceived supplier control decreases perceived risk in a supplier selection situation.

Managerial risk propensities can also influence the degree to which risk is perceived. In this study, risk propensity is assumed to be an exogenous, influential factor in how risks are evaluated and what risks are acceptable (Baird \& Thomas, 1985; MacCrimmon \& Wehrung, 1990; Ghosh \& Ray, 1992). Individuals with differing risk propensities will read into and perceive the costs and benefits of selecting available suppliers differently. Decision-makers with high risk propensity focus on and weigh beneficial outcomes of situations more highly than detrimental outcomes, thus overestimating the probability of success relative to failure (Brockhaus, 1980; Sitkin \& Pablo, 1992). This decreases the perception of risk. In their study with student participants, Sitkin and Weingart (1995) find that risk propensity decreases the level of risk perceived in a race car hypothetical situation. 
Supplier selection involves numerous competing factors with varying degrees of potential benefits and risks (Weber et al., 1991; Kull \& Talluri, 2008). Suppliers may offer exceptional quality levels but could also possibly raise their prices (Min, 1994). Similarly, suppliers may guarantee lower prices but may not be able to provide supplies consistently. A supply manager's role is highly analytical, typically involving planning, scheduling, and coordination of supplies. The role involves boundary spanning activities requiring the manager to work closely with customers, marketing, production, and sales departments to ensure smooth production operations (Fredendall, Hopkins, \& Bhonsle, 2005). Supply managers' decisions are consequential to a firm's success and, in particular, supplier selection decisions can have major consequences because of the difficulty in predicting selected suppliers' performance (Wouters et al., 2009). The demands of the role and the dynamic situation of the supply chain environment imply that supply managers cannot simply rely on their analytical skills but also need to draw on their personal judgment. While personal judgment can be influenced by supply chain experience for assessing the risks involved in a supplier selection situation, it is also susceptible to personal biases (Tazelaar \& Snijders, 2013). Specifically, supply managers' tendencies toward risk (risk propensity) will influence their perception of risk.

Sitkin and Weingart (1995) argue that risk propensity is an emergent property of an individual that is persistent but can change over time due to contextual factors. The supply chain environment is highly dynamic and is typically characterized by changes in purchase situations and process, prices of purchase categories and technological changes (Kaufman and Carter, 2006). The dynamism of the supply environment and the uncertainty in predicting supplier selection outcomes make supply managers perceive risk differently depending on whether they lean toward accepting versus avoiding risk. Specifically, it is expected in a supplier selection 
situation under uncertainty that supply managers with high risk propensities will evaluate the situation favorably, attending to the possibility of beneficial outcomes while downplaying the possibility of detrimental outcomes. Conversely, supply managers with low risk propensity will evaluate the situation unfavorably, attending to the possibility of negative outcomes in the situation like late deliveries while downplaying the likelihood of beneficial outcomes. Thus, we offer the following hypothesis.

H6: Supply manager risk propensity decreases perceived risk in a supplier selection situation.

\section{Influences on Supplier Selection Risk Taking}

Our final two hypotheses describe why risk perception and risk propensity influence selection risk taking. Literature has suggested that higher perceived risk induces decision behavior toward less risk (Sitkin \& Weingart, 1995; Kuhberger, 1998). A higher perception of risk in a situation should induce the decision maker to seek less risky, more certain alternatives. Ellis et al (2010) found that high supply disruption risk perceptions lead toward behavior that seeks new supply sources. Similarly, we view high perceived risk as prevalent in supplier selection decisions because of the uncertainty associated with predicting selected suppliers' performance (Talluri, Narasimhan, \& Nair, 2006; Wouters, Anderson, Narus, \& Wynstra, 2009; Riedl, Kaufmann, Zimmermann, \& Perols, 2013).

Supply managers as agents to the firm are tasked with protecting the firm's competitive position (Zsidisin \& Ellram, 2003; Fiegenbaum \& Thomas, 2004). As we noted above, a supply manager's role spans many intra-organizational and inter-organizational boundaries. Thus, any major decision like supplier selection is likely to have major consequences on the firm and will 
likely be guided by a careful assessment of the situation to protect the firm from threats to supply continuity (Craighead et al., 2007). If supply managers perceive high situational uncertainties, they will tend to avoid exacerbating the situation and choose a less risky, more certain supplier. This helps to minimize or avoid the potential negative impact that a risky supply source might have on the various stakeholders with whom the supply manager must contend. This also protects the supply manager's interest as an agent for the company by reducing the likelihood of termination - i.e., employment risk (Wiseman \& Gomez-Mejia, 1998). With a less risky supplier, certainty toward supplier capabilities is increased, thus, perceived threats to supplies are reduced and risks to the supply manager's agency position are alleviated.

H7: Perceived risk in a supplier selection situation decreases the likelihood of selecting a risky supplier.

Supply chain risk studies make the assumption that managers' decision-making behaviors are primarily based on situational and contextual factors, such as product- or market-specific factors (Ellis et al., 2010), compensation schemes (Villena et al., 2009), or risk identification mechanisms (Neige, Rotaru, \& Churilov, 2009). However, management literature has acknowledged that personal risk propensities are influential in managerial decisions (Sitkin \& Pablo, 1992; Ghosh \& Ray, 1997). Sitkin and Weingart (1995) conceptualized risk propensity as an emergent property of the decision maker, thus, can change over time. Risk propensities of supply managers are influenced by their personal characteristics. It is pertinent to note that the supply chain organization is characterized by market mechanisms and structures that encourage profit maximization. This can socialize supply managers to be analytical, decisive, and 
achievement oriented individuals, which influences and is influenced by their risk propensity (Saini \& Martin, 2009).

We argue that the risk propensity of a supply manager is likely to influence the manager's supplier selection decision. For instance, supply managers may choose riskier options because of their willingness to accept the risks for the possibility of rewards (Lee, 1997). Indeed studies have found that certain managers are more predisposed to accept risks than others (Stewart \& Roth, 2001). This predisposition has a strong relation to personality (Nicholson, 2005) since people respond to situations with potential threats differently. This explains why certain people engage in high risk business ventures and innovations while others do not (Stewart $\&$ Roth, 2001). While supplier selection decisions are associated with potential risks like the failure of selected suppliers to meet delivery and price objectives, such decisions can also be rewarding. For example suppliers can deliver cost advantages through sourcing low cost components or help to improve a firm's innovation performance. In supplier selection situations, we expect that supply managers with low risk propensities will tend to deemphasize these opportunities, instead emphasizing the likelihood and magnitude of detrimental outcomes, and more likely avoiding risky suppliers. By contrast, supply managers with high risk propensities will assess the situation favorably by emphasizing the reward aspect of the decision and, therefore, will be more likely to make riskier decisions than those with low risk propensities. Accordingly, we offer the following hypothesis.

H8: Supply manager risk propensity increases the likelihood of selecting a risky supplier. 


\section{METHODOLOGY}

In order to test our hypotheses and ensure that causal inferences can be made regarding the factors of interest (Martin, 2004), we structured a behavioral experiment with practicing managers in accordance with similar supply chain research (Tangpong, Hung, \& Ro, 2010). A behavioral experiment was preferred because it allows the manipulation of events that capture participant responses to different scenarios. Our approach randomly assigned participants to different one-shot, hypothetical, supplier selection scenarios. Participants were asked to make a selection and answer questions about the scenarios and themselves. Our experimental design follows recommendations by Rungtusanatham, Wallin, and Eckerd (2011). Specifically, our predesign stage assured alignment with previous studies on decision-making behavior under uncertainty (Puto, 1987; Sitkin \& Weingart, 1995) and that sourcing categories followed descriptions commonly found in supply management literature (Kraljic, 1983; Olsen \& Ellram, 1997; Monczka et al., 2009). In our design stage, we assured the common text for the contextual setting was invariant across all scenarios and avoided demand characteristics - i.e., avoiding cues as to the expectations of the experiment (Martin, 2004). Also, in our post-design stage a pretest was conducted with business undergraduate students from a large research university in order to refine the experimental design, improve the measurement model, and assure manipulation validity (Rungtusanatham et al., 2011). Additionally we simplified the description of the experimental factors as much as possible and presented the purchase categories in a $2 \mathrm{X} 2$ matrix to ensure that responding managers would have no difficulty understanding the meaning of the related constructs, thus, ensuring validity.

To ensure that voluntary participants served as suitable proxies for real-world decisionmaking and to ensure the generalizability (i.e., external validity) of results, all participants were 
practicing managers with managerial experience from different industries (Bachrach \& Bendoly, 2011). Professionals with supply chain experience were purposefully sought. Enticement was given by informing them of the general research topic that most found interesting. They were also informed that participation will involve a hypothetical scenario and that their individual scores relative to other responses would be anonymous. Participants were affiliated with the university through industry-university consortiums. A total of 119 useable responses were collected over two months, giving about 20 respondents per simultaneously estimated structural parameter, exceeding similarly designed research (Bolt, Killough, \& Koh, 2001; Wang \& Benbasat, 2008). Over 95 percent of the participants were or had been a supply chain professional (i.e., actively involved in purchasing, operations, and/or logistics). Additionally, 93 percent of participants had over five years of work experience, with 60 percent having eleven years or more. Most participants were over 35 years old, and 73 percent were male. A range of industries was represented (37 percent manufacturing and 63 percent services), with the most participants from the healthcare sector (32 percent).

An anonymous, online-survey approach was used to aid external validity and avoid Hawthorne effects from a laboratory environment (Gould, 2001). Participants could not re-enter the survey once departed. Because we purposely sought participants with supply chain experience, random selection was not possible. However, to avoid confounding the data, we used an online tool to randomly assign treatment conditions to participants (Shadish, Cook, \& Campbell, 2002). This helped ensure causal interpretation by removing possible systemic differences across treatments caused by extraneous factors (Perdue \& Summers, 1986).

\section{Structure of Experiment}


The experiment consisted of four steps. In the first step, managers were presented with an informed consent as prescribed by institutional review board (IRB) requirements for humansubject experiments. The general nature and intent of the experiment were given (i.e., to improve understanding of supplier selection processes) without alluding to uncertainty in decision-making to avoid demand characteristics. Demographic questions were also part of this section. Next, participants were required to acknowledge that they had read a statement that informed them that they will next be presented with a common way to segment sourcing categories and to take their time reviewing the categories; this emphasized the sourcing category importance and context difficulty manipulation.

\section{Manipulations}

In the second step, the basis for the first manipulation was given. Managers were given the information with a $2 \mathrm{X} 2$ table of importance and difficulty, with category names in each cell as shown in Figure 2. Participants were requested to read the following statement:

"Selecting suppliers for a product or service can be complicated. Tools can help structure information so that effective decisions can be made. One common tool is called the 'portfolio analysis matrix' that helps segment purchases into four types: strategic, routine, leverage, and bottleneck. Decisions can be made based on the importance and difficulty of the purchase. Importance is based on the potential value in terms of total spend or strategic impact, while difficulty is based on the challenges in procurement in terms of complexity or riskiness."

The third step involved presenting the hypothetical situation (an example is shown in

Figure 3) to the managers. Participants were first asked to consider themselves as a mid-level buyer making a long-term selection between computer-component Suppliers A and B that will deliver somewhat frequently, but that the manager has minimal post-decisional control over the decision. This low degree of control is constant across all scenarios and was emphasized in order to detect illusions-of-control as manipulated in the experiment. Also, using a mundane 
"computer component" avoids affective influences, yet is familiar and generic enough to both service and manufacturing employees to be applicable to various spend categories.

To differentiate between the uncertainties of outcomes associated with each supplier, all the scenarios stated that the hypothetical purchasing company emphasizes cost and delivery, and that these two dimensions should be used to select Supplier A or B. We avoided using quality because of its potential affective influence (Luce, Payne, \& Bettman, 1999). Regarding cost, supplier-A guarantees a total price reduction of five percent over the duration of the contract, while Supplier-B is pursuing unproven process innovations that have an even chance of lowering prices by twenty percent over the contract duration or not at all. The expected value for selecting Supplier-A is a five percent price reduction, with no uncertainty, while the expected value for selecting Supplier-B is a ten percent price reduction with associated uncertainty. Thus, according to our definition, choosing Supplier-B would be an indicator of increased selection risk taking. Regarding delivery, Supplier-A always has about one out of ten orders delivered late, while Supplier-B mostly delivers on-time except for a couple of months where four out of ten orders are late. The expected value for selecting Supplier-A is ten percent late delivery with no uncertainty, while the expected value for selecting Supplier-B is near zero percent late delivery with some uncertainty. Thus, according to our definition, choosing Supplier-B for this reason also indicates increased selection risk taking. Thus, both dimensions point to Supplier-B as having more downside risk and more upside potential.

Insert Figures $2 \& 3$ here 
Eight scenarios were randomly assigned to induce three factor manipulations: four categories representing low-high conditions of importance and difficulty, and two compensation schemes representing low-high proportions of contingent pay (see Table 2). To induce the sourcing category manipulation, managers were informed of the type of category by stating its label (i.e., routine, bottleneck, leverage, or strategic) and then reiterating the attributes described in Figure 2 regarding its level of importance and difficulty (see Table 3). To induce proportion of contingent pay, managers were informed of their hypothetical base salary and bonus compensation; with a larger bonus relative to base pay inducing a higher proportion of contingent pay. For high contingent pay, the manipulation was "it is important to note buyers are paid a mid-level base salary, but with bonuses available if they show significant cost-reductions and service improvements year-over-year." For low contingent pay, the manipulation was "it is important to note that buyers are paid a high base salary with no bonuses." Lastly, managers were required to acknowledge that they understand the basic supplier differences, type of purchases, and degree of involvement before being able to go to the next section.

Insert Tables $2 \& 3$ here

\section{Measures of Key Variables}

The fourth step consisted of psychometric questions about managers' perceptions of situational characteristics and required participants to make specific supplier selections and give the rationale for their choices. Because our participants were practicing managers, we limited the number of measurement items to avoid fatigue while assuring content validity by adapting items 
from previous studies to our context (Gould, 2001). Measures were also included for manipulation and other validity checks (discussed below). To prevent common method variance, reverse coding was employed and questions for each factor were dispersed to avoid spatial proximity bias (Podsakoff, MacKenzie, Lee, \& Podsakoff, 2003). Participants are asked to rate their level of agreement to a set of statements based on the scenario information (1=strongly disagree, 7 = strongly agree). The a priori measurement model's preliminary 10 items, which had been refined from the aforementioned pretest, was assessed using confirmatory factor analysis (CFA). We found one item necessitated removal because of poor psychometric properties. At least two-items per construct exist, providing an acceptable measurement structure with acceptable reliabilities and reflecting the theoretical content (Hair, Anderson, Tatham, \& Black, 1998, p.598). This measurement structure aligns with other decision science research with similar reliability (Case \& Scott, 1998; Kathuria, Murugan, \& Magid, 1999). The details of the measurement items, as well as their reliabilities and sources, are shown in Table 4 and are discussed in the results section.

We note the final dependent variable selection risk taking is measured using continuous and dichotomous items. The continuous measure that is used in the analysis is based on a Likert scale ( $1=$ strongly disagree, $7=$ strongly agree). The binary measure asks participants to select between Supplier-A and Supplier-B based on the scenarios and to provide a rationale for their decisions. This binary measure is included for triangulation and validation purposes.

\section{Control and Validation Variables}

In addition to the key variables, additional data were collected for validation and control variables. The following demographic variables were collected because of potential biases 
toward risk taking: gender (Harris, Jenkins, \& Glaser, 2006); age (Nicholson, 2005); industry context (Miller \& Chen, 2004); understanding (Anderson \& Mellor, 2009); and experience (Halpern-Felsher, Millstein, Ellen, Adler, Tschann, \& Biehl, 2001). Experience is especially important as individuals' behavior towards risk can change over time (Sitkin \& Weingart, 1995). Previous studies note the importance of experience because decision makers draw from past successful decision strategies (Beach \& Mitchell, 1978; Riedl et al., 2013). In particular, the role of experience when operating in turbulent, uncertain, and dynamic environments, such as in supplier selection situations, has been recognized (Dane \& Pratt, 2007; Tazelaar \& Snijders, 2013). Supply managers with more years of experience in relevant supply chain activities will be able to recognize or spot potentially problematic suppliers more than managers with relatively less years of supply chain experience. In this study, we measured the number of years of supply chain experience because as managers gain more years of supply chain experience, which likely includes supplier selections, they are more likely to make well-informed decisions, influencing supplier selection risk taking. Therefore, years of supply chain experience is of particular interest in our model.

Finally, responses to psychological questions pertaining to personal purchasing risk propensity from consumer behavior research (Raju, 1980) were collected to assess for confounding effects (Bachrach \& Bendoly, 2011). Personal purchasing risk propensity questions include: "I would buy products that I only know a lot about to avoid making a mistake", and "If I were to buy a mobile phone, I would buy only a well-established brand". These are used in our model validation.

\section{Validity Checks}


Our pre-test on two different samples of students (those with prior knowledge of purchase categories as described and classified in the study (Olsen and Ellram, 1997) versus those without prior knowledge) reveals no significant difference in relation to key variables suggesting a common understanding of how we described and presented the factors used in the experimental design. The pretests with business student participants also revealed that the participants' decisions did not appear to take into consideration or be affected by the proportion of contingent pay manipulation. Although we changed the wording and emphasis in the managerial study, to verify that our intended manipulation is transparent and interpretable, we also included the following items in the survey for a manipulation check: "My income will vary based on my decision" and "The supplier I select will affect my personal wealth," with a significant difference between low and high proportion of contingent pay $(\Delta=2.62, t=10.54, p<0.001)$. To assure Supplier-B was associated with more uncertainty or risk, we assessed the rationales that participants provided for their selection and found 80 percent differentiated Supplier-B as the more uncertain and/or more risky (see Appendix-A for the details on our text analysis).

To assess internal validity, checks were conducted to ensure that no confounding effects existed with the treatment level to inadvertently have a direct impact on the unexpected factors in the conceptual model (i.e., risk propensity and perceived supplier control). Factor item values were averaged to form factor scores. The t-tests revealed no significant differences between lowhigh manipulations of the three factor treatments: sourcing category importance (t-values ranged from -0.918 to 0.411 ); sourcing context difficulty (t-values ranged from -.905 to 1.012); and proportion of contingent pay ( $\mathrm{t}$-values ranged from -0.024 to 0.452 ). In summary, no confounding effects were detected. 
Finally, to assess external validity, participant and ecological validity checks were performed (Gould, 2001). Checks were conducted to detect if participant industrial affiliation, personal purchasing risk propensity, value of money, and other demographic characteristics were confounding the experiment. Industry biases were assessed using a similar approach as the confounding check above. No highly significant $(p>0.05)$ differences between manufacturing and services were found (t-values ranged from -1.315 to 1.821 ) although risk propensity was higher in services than manufacturing at $p=0.071$. Checks between healthcare and non-healthcare similarly revealed no highly significant differences (t-values ranged from -1.668 to 0.040 ) although risk propensity was higher in healthcare than in non-healthcare at $p=0.098$. We also checked to see if manipulations were biased by personal purchasing risk propensity, and no significant differences were found. Finally, assessments regarding supply chain position, work experience, age, and gender showed no significant factor mean differences. In sum, following the basic tenets of rigorous behavioral experimentation in operations management research, we validated the experimental design to support the generalizability of our subsequent analysis.

\section{RESULTS AND ANALYSIS}

We followed the two-step method for analyzing structural equations models (SEM), where we first refined and assessed a measurement model for appropriate psychometric properties, and then tested a structural model for appropriate fit and hypothesis testing using the structural parameters (Anderson \& Gerbing, 1988). An approach for SEM testing in experimental designs was followed where the estimation method uses univariate tests of treatment variables (Bagozzi $\& Y i, 1989)$. 
Interestingly, we found that managers in general behave in a risk-averse manner. That is, 73.5 percent of managers selected Supplier-A which is associated with low uncertainty. This is the case even though Supplier-B has a higher expected value. Previous studies have found that managers in different functions display differing risk-taking behavior, and in this situation most managers preferred the safer supplier even though the expected value of Supplier-B was higher. This result is explored further in the discussion section. It should be noted that this pattern held regardless of current supply chain position, work experience, age, and gender.

\section{Measurement Model}

The CFA conducted used a mean-covariance structure in line with Bagozzi and Yi (1989) in EQS. Only the continuous, measured factors were included at this stage since the binary, manipulation factors were to be entered subsequently. The fit statistics show adequate fit with $X^{2}$ $=26.283(26) p=0.447, \mathrm{CFI}=0.999, \mathrm{GFI}=0.957, \mathrm{RMSEA}=0.010(0.000,0.077)$. All loadings are significant and above 0.500 (see Table 4). We find that dispersing the factor-items in the survey avoided method bias. Specifically, the Harman's one factor assessment shows just $31 \%$ of variance explained. Furthermore, a CFA allowing items to load on a latent common methods factor (Podsakoff et al., 2003) is not significantly different $\left(\Delta \chi^{2}=14.7\right.$ (12) $\left.p>.10\right)$, does not change structural parameter significances, and only modifies the significant parameter values on average by $2 \%$. In addition, adequate construct reliabilities above the 0.5 threshold (Fornell \& Larcker, 1981) are achieved, with Cronbach alphas near the preferred values. Further tests also showed acceptable convergent and discriminant validity (Fornell \& Larcker, 1981). Item-level descriptive statistics and correlations are shown in Table 5. 
Insert Tables 4 and 5 here

\section{Hypothesis Tests}

The Bagozzi and Yi (1989) approach uses a mean-covariance structure to create a system of equations to test hypotheses among dummy manifest variables representing low-high levels among the three experimental factors - sourcing category importance, sourcing context difficulty and contingent pay. The goal is to focus on the means, instead of covariances, in order to analyze the hypothesized experimental effects on risk perception and perceived supplier control. The benefit of this approach is that it simultaneously tests the nomological network of effects among the factors. In EQS, this structured-mean approach is accomplished through use of the V999 constant to estimate the factor mean (Bentler, 1995). Dummy variables are expressed as exogenous latent variables with a single indicator and no residual. For further control, we assess direct links from the experimental factors to selection risk-taking to account for how these factors objectively change or influence the managerial decision-making. This was done to understand or isolate the real effects of the cognitive factors on selection risk taking. Supply chain experience is also freely estimated for its effect on selection risk-taking.

Analysis was done with maximum likelihood estimation using the augmented moment matrix instead of the typical covariance matrices; this specification enables one to analyze the means of observed dependent variables as functions of the dummy experimental factors (Bagozzi \& Yi, 1989). The process to test the effects of the three experimental factors involved constraining the paths of the exogenous factors equal to zero and then performing a Lagrange Multiplier (LM) univariate chi-square test to determine if releasing the zero-value path constraint 
improved model fit. In this manner, the paths to perceived risk from sourcing category difficult (H1), sourcing category importance $(\mathrm{H} 2)$, and contingent pay (H3), as well as the path to perceived supplier control from contingent pay (H4), were tested. The other paths were tested following standard SEM structural parameter significance tests. Because of our directional hypotheses and our low sample size relative to the number of parameters tested, we used a $p<0.10$ to indicate statistical significance. The overall model results are presented in Figure 4. The fit of the model is adequate with $X^{2}=60.132(51) p=0.178, \mathrm{CFI}=0.973, \mathrm{GFI}=0.924$, $\operatorname{RMSEA}=0.033(0.000,0.071)$

The first four hypotheses relate to the three experiment factors. Hypothesis 1 positing that sourcing category difficulty increases perceived risk is supported $(\beta=0.326, p<0.01)$. Hypothesis 2 positing that sourcing category importance increases perceived risk is also supported $(\beta=0.178, p<0.10)$. Hypothesis 3 positing that contingent pay decreases perceived risk is not supported as the LM test did not detect a significant univariate chi-square improvement $\left(\Delta \chi^{2}=0.789\right.$ (1) $p>.10$, represented as "n.s." in Figure 4). Hypothesis 4 positing that contingent pay increases perceived supplier control is supported $(\beta=0.234, p<0.01)$. Thus, three of the four hypothesized experimental factor effects are supported, indicating how the situational context influences perceptions during supplier selection.

The remaining hypotheses investigate the relationships among cognitive processes and selection risk taking. Hypothesis 5 positing that perceived supplier control decreases perceived risk is supported $(\beta=-0.218, p<0.10)$. However, Hypothesis 6 positing that risk propensity decreases perceived risk is not supported $(\beta=-0.105, p>0.10)$. Hypothesis 7 positing that perceived risk decreases selection risk taking is supported $(\beta=-0.202, p<0.05)$; as is Hypothesis 8 positing that risk propensity increases selection risk taking $(\beta=0.567, p<0.01)$. The above 
results suggest that while risk perception is influential in supplier selection behavior, concomitant factors like perceptions of control and risk propensity diminish risk perception's dominance in the cognitive model.

Finally, to control for the direct effect of the experimental factors on selection risktaking, we performed the LM test as described above and we found no univariate evidence indicating such direct influence. To further verify this we allowed all experimental factors to freely relate to selection risk taking and the full model showed no significant improvement $\left(\Delta \chi^{2}=0.838(3), p>0.10\right)$ with no substantial change in sign or significance of the parameters of interest. This result supports the importance of risk perception and propensity in selection risktaking. Interestingly, the relationship between supply chain experience and selection risk-taking is found to be significant $(\beta=0.129, p<0.10)$, suggesting that more experience in supply management leads managers to be more risk accepting in selection decision-making.

\section{Insert Figure 4 here}

\section{DISCUSSION AND CONCLUSIONS}

In this paper we theorized and largely confirmed that sourcing category characteristics, the manner of compensation, and personal risk propensity influences a manager making a supplier selection under uncertainty. Our study supports the applicability of behavioral decision theory and the behavioral agency model in a supply chain context, and provides a cognitive and behavioral model that can be built upon by future research. In addition, several theoretical implications result from our findings. 
We found that participants, who predominantly were practicing supply chain managers, generally avoid selecting a supplier with less certain outcomes even when that supplier possesses higher expected returns. This result suggests there may be general risk-aversion in managers when selecting supply partners. Uncertainty may be interpreted as unreliability, and many supply managers are likely to be extra sensitive to hints of insecure supply continuity (Goldfeld, 1999). Of course, uncertainty avoidance may come at the expense of innovations and rewards (Tomlin, 2006), which is part of the context of this study.

Our empirical modeling results reveal that both sourcing category difficulty and importance lead to perceptions of risk in the selection situation. That is, categories that are either deemed more important or more difficult are perceived as more problematic than components that are less so. In the case of category importance, supply managers likely view greater threats, both for the firm and personally, as the criticality of the category to the business in terms of its cost and the extent to which the business relies on the category increases. The importance and criticality of the category implies that there is little slack or room for failure. A supply failure will be highly consequential to the business because of its impact on critical organizational need, thus, increasing the decision-maker's perception of risk for such categories. In the case of category difficulty, the perceived possibility of problems likely increases, leading managers to perceive higher risks. The novelty of the category and the complexity involved in sourcing a difficult purchase category create a problematic sourcing context because of the uncertainties involved. Thus, it may not be feasible for a supply manager to quickly or easily implement contingencies when disruptions to the supply of a difficult purchase category occur, thereby increasing the supply manager's perception of risk. 
Our findings builds on the work of Ellis et al. (2010) who found that that sourcing characteristics classified as difficult and important increase risk perceptions. Whilst Ellis et al. (2010) investigated risk perception in a currently supplied component, we show that risks are perceived prior to establishing a supply partner. In other words, we show that supply managers are likely to be aware of, or at least perceiving of, potential threats before entering into supply arrangements based on the classifications of the intended purchase categories. If true, such a reality will oblige them to choose either to accept or avoid such risk in selecting suppliers for different categories. Our study points to the possibility that various conditions in the supplier selection decision reveal potential hazards to supply managers prior to making their decision.

Contrary to our expectations, we found no significant link between contingent pay and risk perceptions. Prior work has inferred that compensation schemes directly influence the threats supply managers perceive, both for the firm and personally, when making decision for their company (Villena et al., 2009). We don't find a direct link to risk perceptions. This suggests that decision makers do not expect less wealth with a higher proportion of contingent pay; their sense of risk seems unaffected by compensation scheme. While this implies either confidence in the ability to attain bonuses or a lack of confidence in retaining a high base salary, contingent pay is not shown to have a direct bearing on how much risk a supply manager perceives in supplier selection.

Yet, we find that the proportion of contingent pay increases perceived supplier control. Contingent pay gives an illusion of control even though the facts suggest otherwise. As the name implies, contingent pay is designed to depend on the decision maker's behavior, thus giving the decision maker a sense of control. The more a supply manager's pay depends on the results of a manager's decision, such as when PPV compensation mechanisms exist, the more the illusion 
that the manager has post-decisional control over consequences of supplier selections. Firms should consider these, perhaps, unintended consequences when designing compensation schemes, particularly because we also found that perceived supplier control decreases perceived risk. Managers are less likely to see a supplier selection decision as a risky situation if they believe that they have post-decisional control over their decisions (Pitz, 1992). In other words, a manager may have an erroneous belief that consequences of a supplier selection can be reversed over time. Analogously, just as consumers may purchase a retail item with uncertain reliability because they believe the item can be returned, managers may discount the downside aspects of a supplier selection situation if they believe problems can be efficiently corrected - such as through renegotiations or development. Thus, perceived post-decisional control is likely to encourage more risk taking (i.e., accepting) in supplier selections.

Our results also show that perceived risk decreases selection risk taking, which is in line with previous studies that investigated similar links in other contexts (Sitkin and Weingart, 1995). This result shows that when cognitive and behavioral factors induce perceptions of risk in an uncertain supplier selection situation, managers will tend to choose a supplier with more predictable outcomes in order to protect themselves as agents and to protect the firm. The converse is suggestive - cognitive factors that reduce risk perceptions can lead toward selecting uncertain suppliers that increase the likelihood of supply disruptions. Zsidisin and Wagner (2010) have found that supply chain resiliency practices reduce risk perceptions even in the presence of high supply disruptions. These implications may explain why firms continue to discover risks in their supply base.

Finally, we find that risk propensity increases selection risk taking in line with Sitkin and Pablo's (1992) arguments, suggesting that the willingness to bear risks for the possibility of 
gains induces supply managers to select uncertain suppliers (Kocabasoglu, Prahinski, \& Klassen, 2007). This finding, however, contradicts Sitkin and Weingart (1995) who found that the effect of risk propensity on risk taking was fully mediated by risk perception. Sitkin and Weingart's (1995) study suggests that managers with high risk propensity would make supplier selection decision solely based on how they perceive the inherent risks. By contrast, our study finds that supply managers' biases (risk propensity) could influence how they make decisions regardless of how they perceive inherent risks. In other words, we find a direct link between risk propensity and supplier selection risk taking. Unlike Sitkin and Weingart, who tested their model in a piecemeal fashion, we used a more comprehensive structural approach that provided a true test of relationships among interconnected variables. Indeed, the direct link between risk propensity and risk taking suggests that, other than risk perception, there are underlying processes through which risk propensity affects risk taking that requires further examination.

Our study makes multiple contributions to literature. First, our study confirms the relationship between risk perception and risk-taking behavior in supplier selection, extending the results of previous studies (Sitkin and Weingart, 1995; Ellis et al. 2010) and underscoring the importance of managerial risk perceptions in supply management. Second, our finding that sourcing category importance and difficulty change a manager's risk perception reveals that cognitive processes play an important role sting as supply managers make key decisions in their supply chains. Third, our integration of perceived supplier control extends Shapira's (1995) concept of post-decisional control into risky supplier selection behavior, and takes a nascent step in addressing how to incorporate the concept into decision science literature. Fourth, the concept of post-decisional control was specifically linked with contingent pay to show how the BAM can be extended to incorporate the illusions of control concept - a variable often neglected in 
decision theory research. Finally, our finding that relates risk propensity to selection risk taking builds on previous studies that investigated the determinants of decision-making under uncertainty, thus, representing an extension into the supply chain context. In particular, contrary to previous assumptions about how supply managers make decisions, it underscores that psychological characteristics help explain why supply managers accept or avoid suppliers with more uncertainty.

\section{Managerial Implications}

Our findings highlight the importance of categorizing components in supply management, giving supply chain executives some insight into what unexpected factors might influence supplier selection decisions in different situations. In particular, this study highlights the role that characteristics of a sourcing category play in how risk is perceived as an antecedent of subsequent supplier selections. Because the "difficulty" category influenced perceived risk, managers may be less willing to take risks when selecting suppliers for novel or purchase categories that are difficult to source. Interestingly, because competitors are also likely to face such difficulties and also less likely to take risks, opportunities to potentially gain competitive advantage by being more risk accepting when selecting suppliers for such categories may be missed. Thus, managers should not simply be put off by the seemingly negative consequential effects of a difficult purchase category when making supplier selection decisions. Similarly, when purchase categories are classified as "important," managers may be less willing to take risks when selecting suppliers since they may perceive risks with such purchase categories. The 
implications of these key findings is that supply managers are cognitively affected by both the firm's external and supply market complicatedness, and by the firm's internal and strategic ramifications of making the correct supplier selection. Therefore, supply managers should take these cognitive processes into account in order to assure that selection decisions are being made for the appropriate reasons.

Our study also highlights the need for clarity regarding how compensation schemes affect supply chain managers. As we have shown, contingent pay affects the cognitive processes leading to risk taking. Although our findings comport with Villena et al.'s (2009) empirical results, we find that contingent pay indirectly affects perceived risk through control perception, rather than directly affecting perceived risk. Although more study is required in this area, our results show that compensation schemes that firms use to influence managerial behavior may induce unintended cognitive biases. Rewarding based on contingent pay must be closely monitored to ensure that managers understand the limits of their responsibilities and power as regards post-decisional situations.

Finally, the fact that the risk propensity of managers influences decision-making under uncertainty has implications in terms risk taking in supply management. Sitkin and Weingart (1995) imply that managers take risk mostly because they are unaware that risks exist. Moreover, supply chain literature tends to view supply managers as risk-averse - choosing to avoid risks when they can (Tomlin, 2006). Our descriptive analysis supports this notion that supply chain managers generally prefer to avoid selecting alternatives involving uncertainty. However, our results also show that their risk acceptance is closely tied with their personal risk propensity. The implication is that as risk propensity increases, uncertain suppliers become more attractive even though managers are aware of the downside potential. Supply chain experience does not counter- 
act this effect. At issue is the trade-off between potential rewards and losses. Numerous supply chain studies highlight the competitive advantage attainable through leveraging supplier capabilities. Yet the outcomes from leveraging suppliers are not certain, meaning more risk. Some managers in our study appear to be comfortable accepting a degree of uncertainty. Analytical studies have suggested conditions where accepting uncertain suppliers is optimal (Tomlin, 2006). Yet, the extent to which risk propensity is beneficial remains empirically undetermined. If risk propensity is shown to be a valuable trait, it has an implication for resource allocation, employee selection, recruitment, and development. In sum, our study highlights the need for understanding the cognitive and behavioral processes involved before trying to improve supply manager decision-making.

\section{Limitations and Future Studies}

There are several limitations to this study that must be highlighted in order to motivate future research. First, as with all laboratory experiments, our study created an artificial environment in which situations could be completely controlled. Real world settings are harder to control and more dangerous for the participants, but future quasi-experimentation in the field setting may be possible by manipulating some factors in a true supplier selection situation without allowing a

final decision to be made. In effect, this would extend the time to make the supplier selection, but could give valuable insights to the participants as well as the researchers. Furthermore, we recognize that there is a possibility that managers might not fully understand the descriptions of the experimental factors and other measurements items leading to potential validity issues. In the experimental design we tried as much as possible to ensure the validity of our constructs. For example, we pre-tested the experimental instruments and refined the instruments based on the 
results of our testing. We tried to simplify the description of the experimental factors and also presented them in a $2 \mathrm{X} 2$ matrix to ensure that responding managers would have no difficulty understanding the meaning of the related constructs. Nevertheless, we recognize that there is still a possibility of validity issues, thus, future studies must take extra steps to assure the validity of the measurement items. Second, while our measurement model provided high reliability within our study, future research could consider other factors affecting risk perceptions (e.g. time pressure or the presence of contingency plans), and more items per factor in order to develop even richer cognitive models. For example, it could be argued that the existence of contingency plans for a purchase category could potentially decrease risk perception for selecting suppliers for that category. However, we believe that the existence of contingency plans is more likely to affect actual behavior and not risk perception. For example, a manager may perceive that risks exist for a difficult purchase category, but his/her actions may or may not actually reflect the risk perceived because of the belief that contingencies exist. Nevertheless, we believe that the question of whether contingency plans have effect on risk perception and/or decision-making behavior when such plans are associated with different purchase categories represents an intriguing question and should be investigated in future studies.

Third, this was a one-shot experiment with no performance feedback. Although no learning theory or Bayesian-type updating were integral for this study, future work examining the dynamic learning or knowledge-gaining effects of managers making supplier selections under uncertainty should test the stability of our model and add insights. Finally, supplier selections are not always the decision of a single individual. Often, strategic sourcing teams collectively interview and choose among suppliers. Although our study is limited to the within-person 
influential factors, future work should study the between-person, team-level processes — such as group-think — that influence supplier selection behavior under uncertainty. 


\section{APPENDIX A: TEXT ANALYSIS OF MANAGERIAL RATIONALES}

Participants were asked to provide a rationale for their supplier selection. Comments were aggregated into two texts: those selecting Supplier A versus Supplier B. Participants selecting Supplier B were $40 \%$ more verbose. A latent analysis of the comments indicated that those choosing Supplier B were more likely to use numerical arguments. In addition, as shown in Table A1, participants selecting Supplier B focused almost exclusively on its benefits focusing on opportunities - while giving little support for not selecting Supplier A. In contrast, participants selecting Supplier A took efforts to highlight both the upside of Supplier A and the downside of Supplier B.

Table A1: Supplier-Associated Descriptors within each Characterization-Selection Combination

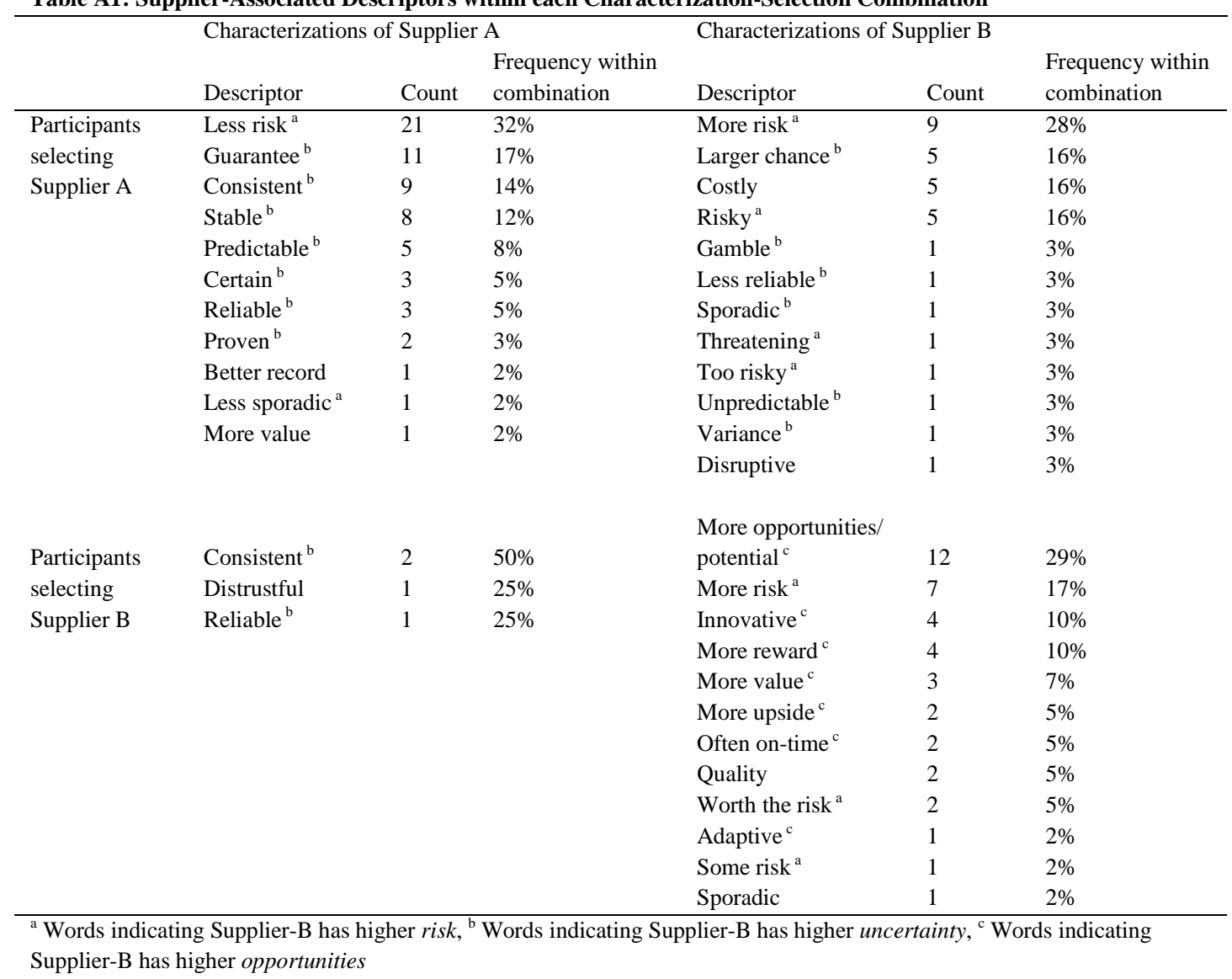

Further, the two texts were analyzed using centering resonance analysis (CRA) (Corman, Kuhn, McPhee, \& Dooley, 2002; Corman \& Dooley, 2006), parsing noun phrases to create word networks that, based on graph and linguistic theories, show coherency through backwards and forwards connection of noun phrases (Grosz, Weinstein, \& Joshi, 1995). CRA measures the importance of a word via its betweeness centrality. Respondents who chose Supplier B were over $50 \%$ more coherent in their collective comments (as measured by the overall "betweeness" centrality of the CRA network) than those who chose Supplier A. Also, arguments of those choosing Supplier B were less diverse than the arguments of those choosing Supplier A. In 
comments from those choosing Supplier A, the most influential words were "risk", "SupplierA", "Supplier-B", "delivery", and "cost". Conversely, the most influential words in comments from those choosing Supplier B were "Supplier-B", "cost", "good", "order", and "risk". By comparing the two networks we further found that "guarantee-reduction-year" and "low-supplyrisk" were influential word triads that existed only in Supplier A comments; while "expectedcost-benefit," "high reward," and "good responsiveness" were unique to Supplier B comments.

Collectively these results suggest that those choosing Supplier B - the more uncertain choice - were more likely to be verbose in their explanation, use numerical arguments, and highlight the potential positive outcomes associated with the choice. Those choosing Supplier A were more likely to cite risk as the main reason for not choosing Supplier B. In other words, those choosing the more uncertain outcome seemed to acknowledge the uncertainty and be more concerned about voicing a strong argument in support of choosing Supplier B, while those choosing the more certain outcome acknowledged the opportunity of the more uncertain choice but said the downside risk was not acceptable, and therefore they could not choose Supplier B. 


\section{TABLES}

Table 1: Nominal Definitions of Constructs Used in the Proposed Model

\begin{tabular}{|c|c|c|}
\hline $\begin{array}{l}\text { Construct } \\
\text { Name }\end{array}$ & Nominal Definition & Additional Notes \\
\hline $\begin{array}{l}\text { Sourcing } \\
\text { Category } \\
\text { Difficulty }\end{array}$ & $\begin{array}{l}\text { The extent to which potential } \\
\text { problems exist due to the } \\
\text { characteristics of the product, } \\
\text { environment, and supply market of a } \\
\text { sourced component (Kraljic, 1983; } \\
\text { Olsen \& Ellram, 1997) }\end{array}$ & $\begin{array}{l}\text { Difficult purchases present threats to the firm and } \\
\text { problems to the manager in assuring proper component } \\
\text { supply (Goldfeld, 1999) }\end{array}$ \\
\hline $\begin{array}{l}\text { Sourcing } \\
\text { Category } \\
\text { Importance }\end{array}$ & $\begin{array}{l}\text { The extent to which a sourced } \\
\text { component is critical to the firm's core } \\
\text { competence or is of high cost relative } \\
\text { to total firm costs (Kraljic, 1983; } \\
\text { Olsen \& Ellram, 1997) }\end{array}$ & $\begin{array}{l}\text { Important purchases can have substantial organizational } \\
\text { consequences and can raise expectations for the manager } \\
\text { in terms of influencing firm performance (Puto, 1987; } \\
\text { McQuiston, 1989; Goldfeld, 1999) }\end{array}$ \\
\hline $\begin{array}{l}\text { Proportion of } \\
\text { Contingent } \\
\text { Pay }\end{array}$ & $\begin{array}{l}\text { The proportion of pay relative to total } \\
\text { compensation that is contingent on } \\
\text { uncertain firm-level events such as } \\
\text { performance outcomes (Wiseman \& } \\
\text { Gomez-Mejia, 1998) }\end{array}$ & $\begin{array}{l}\text { The higher the contingent pay, the closer managerial } \\
\text { compensation can be coupled to firm performance } \\
\text { (Larraza-Kintana, Wiseman, Gomez-Mejia, \& } \\
\text { Welbourne, 2007). }\end{array}$ \\
\hline $\begin{array}{l}\text { Perceived } \\
\text { Supplier } \\
\text { Control }\end{array}$ & $\begin{array}{l}\text { The decision makers' beliefs in their } \\
\text { abilities to have post-decisional } \\
\text { control over the consequences of their } \\
\text { initial supplier selection behavior } \\
\text { (Shapira, 1995). }\end{array}$ & $\begin{array}{l}\text { Perceptions of control have a strong influence on problem } \\
\text { recognition, risk perceptions, and decision-making } \\
\text { (Houghton, Simon, Aquino, \& Goldberg, 2000; Keil et } \\
\text { al., 2007). }\end{array}$ \\
\hline Perceived risk & $\begin{array}{l}\text { A decision maker's overall assessment } \\
\text { of the probabilities and magnitudes of } \\
\text { potential losses associated with a } \\
\text { supplier selection situation (Mitchell, } \\
\text { 1995; Ellis et al., 2010). }\end{array}$ & $\begin{array}{l}\text { Risk is perceived when there is uncertainty and when } \\
\text { negative consequences are salient (Baird \& Thomas, } \\
\text { 1990; Sitkin \& Weingart, 1995). Because organizational } \\
\text { buying poses threats to both the decision-maker and the } \\
\text { firm (Hawes \& Barnhouse, 1987), supplier selection risk } \\
\text { perceptions are assumed to be a composite assessment } \\
\text { (Mittal \& Ross, 1998; Zsidisin, 2003). }\end{array}$ \\
\hline $\begin{array}{l}\text { Risk } \\
\text { Propensity }\end{array}$ & $\begin{array}{l}\text { The tendency of a decision maker to } \\
\text { take or avoid risks (MacCrimmon \& } \\
\text { Wehrung, 1990) }\end{array}$ & $\begin{array}{l}\text { A high risk propensity discounts the downside or heavily } \\
\text { weigh the upside potential of a situation (Krueger \& } \\
\text { Dickson, 1994; Sitkin \& Weingart, 1995). Because risk } \\
\text { propensity is a personal bias that can vary across contexts } \\
\text { (Ghosh \& Ray, 1992; Ghosh, 1994), assess it directly } \\
\text { related to the context of interest (Blais \& Weber, 2006). }\end{array}$ \\
\hline $\begin{array}{l}\text { Selection } \\
\text { Risk Taking }\end{array}$ & $\begin{array}{l}\text { The likelihood of a decision maker to } \\
\text { select a supplier that is associated with } \\
\text { more uncertainty - i.e., more risk but } \\
\text { also more potential benefit (Case \& } \\
\text { Scott, 1998; Tomlin, 2006). }\end{array}$ & $\begin{array}{l}\text { Risk and uncertainty are highly related (Lipshitz \& } \\
\text { Strauss, 1997; Hult et al., 2010). High risk suppliers have } \\
\text { greater uncertainty (cf. Chow \& Haddad, 1991). Supplier } \\
\text { selection risk taking relates to Sitkin and Pablo's (1992) } \\
\text { decision risk in that there is uncertainty about the } \\
\text { potentially significant outcomes of decisions. }\end{array}$ \\
\hline
\end{tabular}


Table 2: Experimental Design

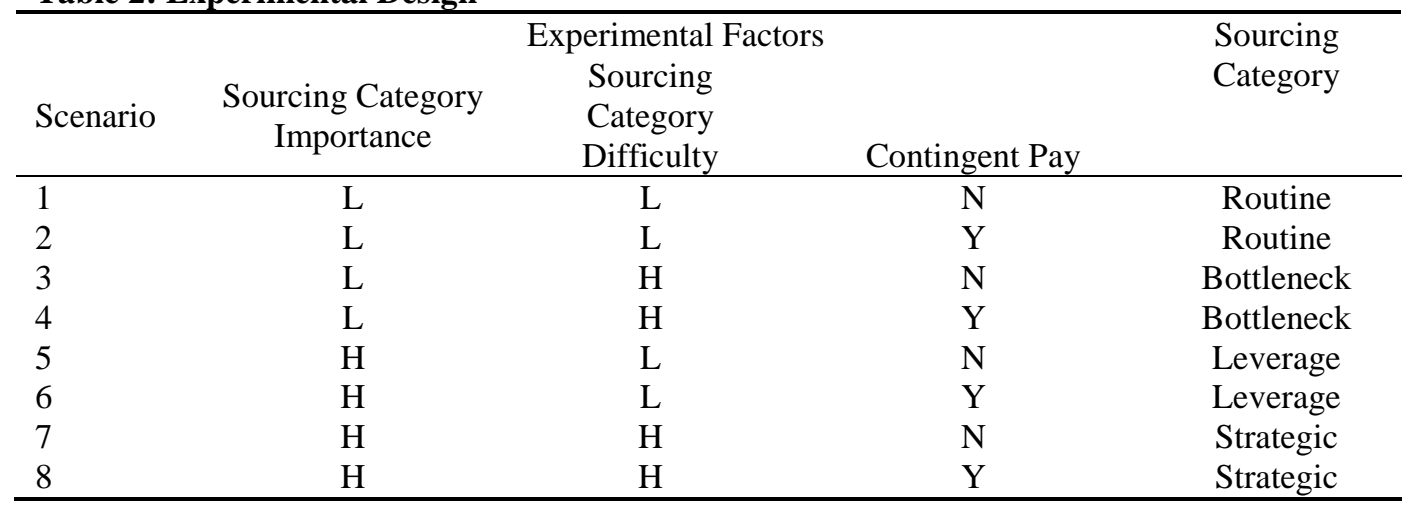

Table 3: Scenario Variations in Sourcing Category Text

\begin{tabular}{|c|c|c|}
\hline & Low Importance & High Importance \\
\hline High Difficulty & $\begin{array}{l}\text { Bottleneck: "Your senior buyer has } \\
\text { informed you that this is a } \\
\text { "bottleneck" category with low overall } \\
\text { spend and low criticality to operations. } \\
\text { However, it is a unique category that } \\
\text { is not easily available - supply } \\
\text { continuity is important. It has complex } \\
\text { specifications and untested processes. } \\
\text { Therefore, it must be managed by } \\
\text { decreasing supplier uniqueness, } \\
\text { marketplace scanning, and supplier } \\
\text { development." }\end{array}$ & $\begin{array}{l}\text { Strategic: Your senior buyer has } \\
\text { informed you that this is a "strategic" } \\
\text { category with high overall spend and } \\
\text { high criticality to operations. Few } \\
\text { qualified suppliers exist because it's } \\
\text { unique and complex. Quality is crucial. } \\
\text { Partnerships with suppliers can help by } \\
\text { increasing their design role. } \\
\text { Contingency plans exist in case things } \\
\text { go wrong. }\end{array}$ \\
\hline Low Difficulty & $\begin{array}{l}\text { Routine: "Your senior buyer has } \\
\text { informed you that this is a "routine" } \\
\text { category with low overall spend, low } \\
\text { criticality to operations and ready } \\
\text { availability. It has many small, } \\
\text { individual transactions for everyday } \\
\text { use; and provides an opportunity for } \\
\text { savings by simplifying and reducing } \\
\text { buying effort, eliminating small- } \\
\text { volume spend, and automating } \\
\text { transactions." }\end{array}$ & $\begin{array}{l}\text { Leverage: "Your senior buyer has } \\
\text { informed you that this is a "leverage" } \\
\text { category with high overall spend and } \\
\text { high criticality to operations. It is } \\
\text { readily available in the supply market, } \\
\text { many alternatives, and ample } \\
\text { inventories exist. There are } \\
\text { opportunities for savings by } \\
\text { maximizing commercial advantage, } \\
\text { concentrating business, and } \\
\text { maintaining competition among } \\
\text { suppliers." }\end{array}$ \\
\hline
\end{tabular}


Table 4: Measurement Model Results

\begin{tabular}{|c|c|c|c|c|}
\hline Construct & Items & $\begin{array}{l}\text { Standardized } \\
\text { Loading }\end{array}$ & t-value & $\begin{array}{c}\text { Intercept } \\
\text { Value }\end{array}$ \\
\hline \multicolumn{5}{|c|}{ Risk Propensity $\left(\rho_{\eta}=0.546^{\mathrm{a}}, \alpha=0.541\right)$. Sources (Sitkin \& Pablo, 1992; Sitkin \& Weingart, 1995) } \\
\hline \multicolumn{5}{|c|}{ In the above supplier selection scenario, if the decision is very } \\
\hline \multicolumn{5}{|c|}{ important for your company's success, rate your likelihood to - } \\
\hline & $\begin{array}{l}\text { Q2.08 choose a less risky supplier because it has a major } \\
\text { impact on the company's strategic direction (reverse) }\end{array}$ & $0.747^{* * *}$ & 5.672 & 2.676 \\
\hline & $\begin{array}{l}\text { Q2.09 strategically choose a supplier even though it may } \\
\text { cause problems }\end{array}$ & $0.518^{* * *}$ & 4.508 & 3.509 \\
\hline & $\begin{array}{l}\text { Q2.10 Support a selection decision even though analyses } \\
\text { were done that lacked significant information }\end{array}$ & --- & & \\
\hline \multicolumn{5}{|c|}{ Perceived Supplier Control ( $\left.\rho_{\eta}=0.735^{\mathrm{a}}, \alpha=0.689\right)$ : Sources (Simon, Houghton, \& Aquino, 2000; Forlani, 2002) } \\
\hline & $\begin{array}{l}\text { Q1.01 It appears I have very little control over what } \\
\text { happens after I make the decision (reverse) }\end{array}$ & $0.648^{* * *}$ & 5.157 & 3.148 \\
\hline & $\begin{array}{l}\text { Q1.08 This situation allows me to actively engage with the } \\
\text { supplier I select }\end{array}$ & $0.864^{* * *}$ & 5.994 & 3.667 \\
\hline \multicolumn{5}{|c|}{ Risk Perception ( $\left.\rho_{\eta}=0.700^{a}, \alpha=0.705\right)$. Sources (Sitkin \& Weingart, 1995; Ganzach, Ellis, Pazy, \& Ricci-Siag, 2008) } \\
\hline & Q1.04 There seems to be a lot of risk in this situation & $0.648^{* * *}$ & 5.951 & 4.028 \\
\hline & $\begin{array}{l}\text { Q1.11 There is little risk in the decision I face here } \\
\text { (reverse) }\end{array}$ & $0.658^{* * *}$ & 6.031 & 4.685 \\
\hline & Q1.17 This scenario can be characterized as risky & $0.676^{* * *}$ & 6.168 & 4.194 \\
\hline \multicolumn{5}{|c|}{ Selection Risk Taking $\left(\rho_{\eta}=0.840^{\mathrm{a}}, \alpha=0.841\right)$} \\
\hline & Q1.06 Supplier A is the better choice (reverse) & $0.905^{* * * *}$ & 9.578 & 3.019 \\
\hline & Q1.13 I would probably select supplier B & $0.807^{* * *}$ & 8.504 & 3.204 \\
\hline
\end{tabular}

Fit Statistics: $\chi^{2}=26.283(26) p=0.447, \mathrm{CFI}=0.999, \mathrm{GFI}=0.957, \mathrm{RMSEA}=0.010(0.000,0.077)$

${ }^{*} \mathrm{p}<.0 .10,{ }^{* *} \mathrm{p}<.0 .05,{ }^{* * *} \mathrm{p}<.0 .01,{ }^{\mathrm{a}} \rho_{\eta}$ is construct reliability (Fornell \& Larcker, 1981) 
Table 5: Item Correlations and Descriptive Statistics

\begin{tabular}{|c|c|c|c|c|c|c|c|c|c|c|}
\hline & Q1.01 & Q1.04 & Q1.06 & Q1.08 & Q1.11 & Q1.13 & Q1.17 & Q2.08 & Q2.09 & $\begin{array}{l}\text { SCM } \\
\text { Exp. }\end{array}$ \\
\hline Q1.01 & 1 & & & & & & & & & \\
\hline Q1.04 & -.093 & 1 & & & & & & & & \\
\hline Q1.06 & $.193^{*}$ & -.101 & 1 & & & & & & & \\
\hline Q1.08 & $.526^{* *}$ & -.113 & $.256^{* *}$ & 1 & & & & & & \\
\hline Q1.11 & .050 & $.455^{* *}$ & -.068 & -.058 & 1 & & & & & \\
\hline Q1.13 & $.188^{*}$ & -.184 & $.732^{* *}$ & $.196^{*}$ & -.159 & 1 & & & & \\
\hline Q1.17 & -.183 & $.439^{* *}$ & -.115 & $-.201^{*}$ & $.442^{* *}$ & -.155 & 1 & & & \\
\hline Q2.08 & .148 & -.080 & $.428^{* *}$ & $.221^{*}$ & -.069 & $.391^{\text {** }}$ & -.045 & 1 & & \\
\hline Q2.09 & $.233^{*}$ & -.101 & $.278^{* *}$ & .140 & -.186 & $.274^{* * *}$ & -.066 & $.384^{* *}$ & 1 & \\
\hline SCM Exp. & .108 & -.019 & .177 & .118 & .055 & .015 & .029 & .032 & .188 & 1 \\
\hline Mean & 3.170 & 3.970 & 3.051 & 3.640 & 4.625 & 3.220 & 4.180 & 2.693 & 3.550 & $2.740^{\mathrm{a}}$ \\
\hline Std. dev. & 1.882 & 1.461 & 1.529 & 1.942 & 1.465 & 1.736 & 1.577 & 1.198 & 1.558 & 1.581 \\
\hline
\end{tabular}

${ }^{\mathrm{a}} 1=1-5 \mathrm{yrs}, 2=6-10 \mathrm{yrs}, 3=11-15 \mathrm{yrs}, 4=16-20 \mathrm{yrs}, 5=21-25 \mathrm{yrs}, 6=26+\mathrm{yrs}$ 


\section{FIGURES}

Figure 1: Theoretical Model

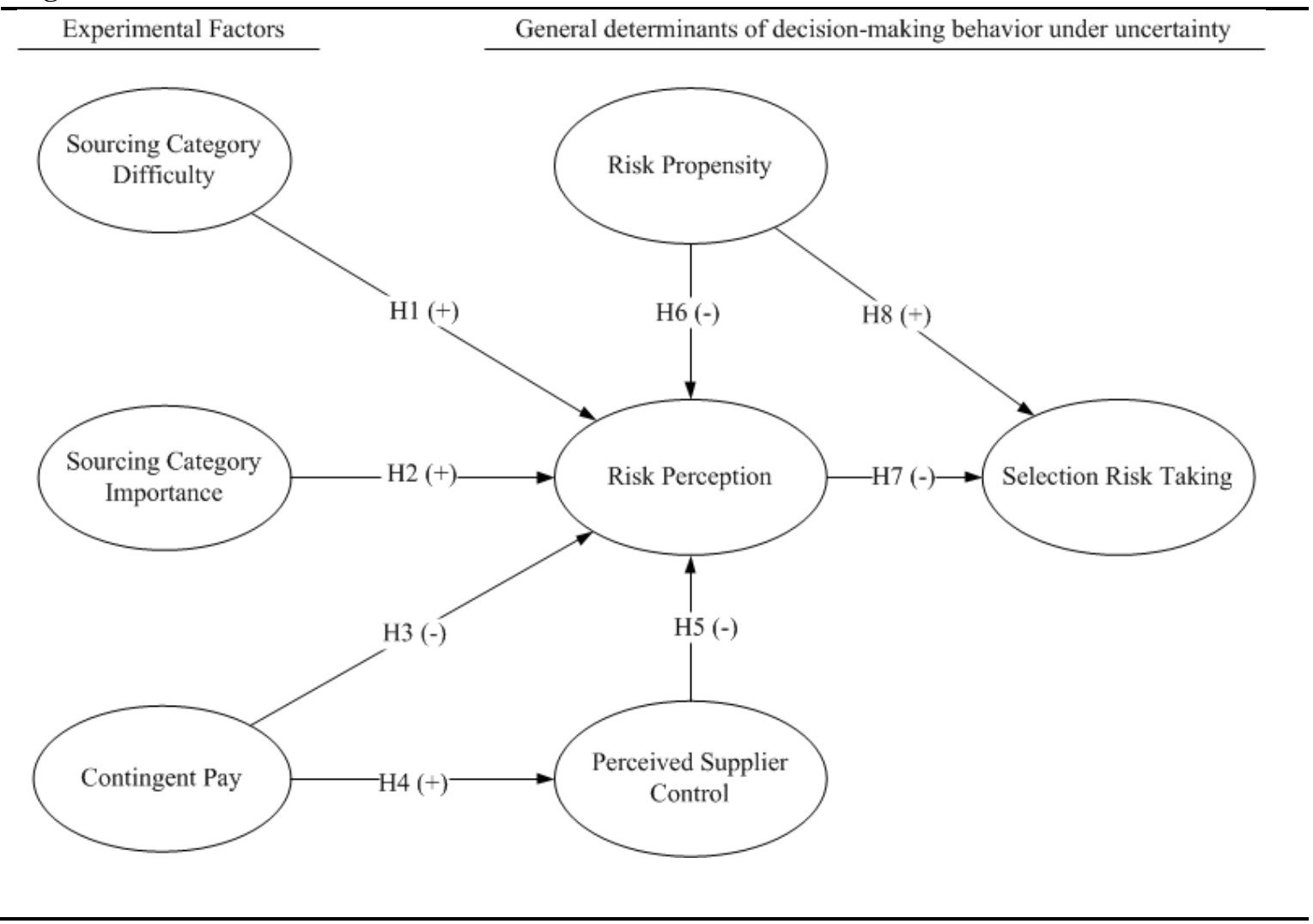


Figure 2: Common Text Explaining Sourcing Categories

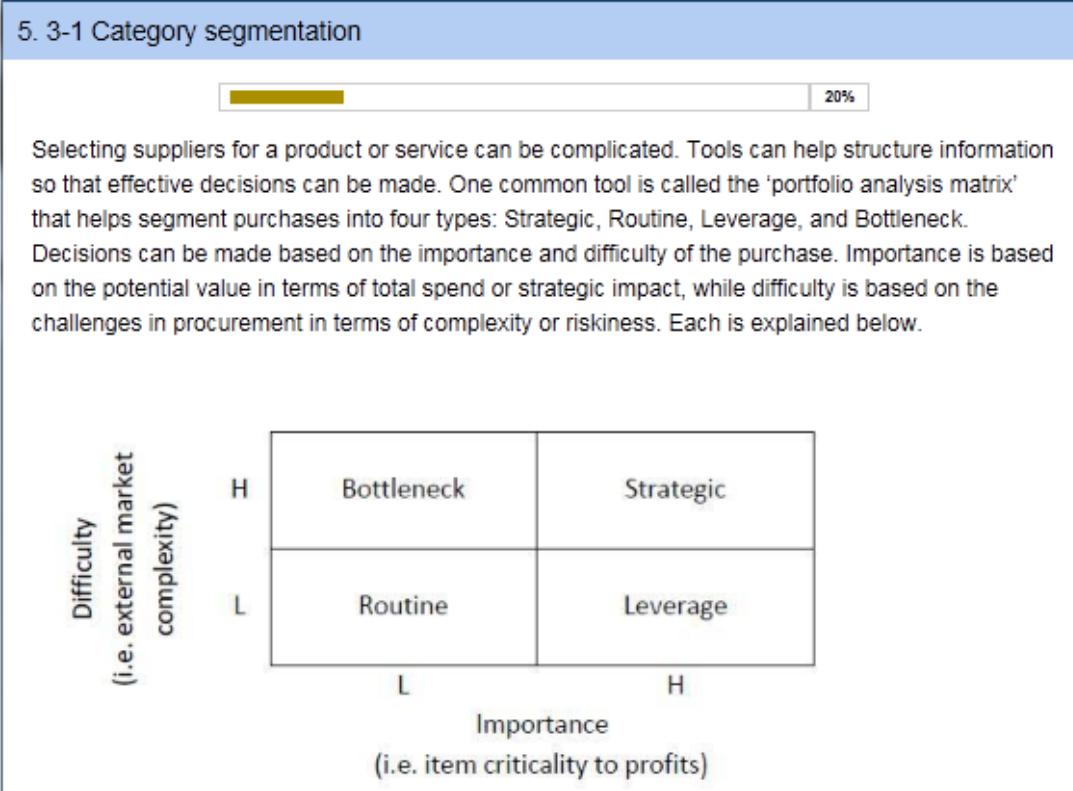

ROUTINE: This category has a low overall spend, is not critical to the firm's operations and is readily available in the supply market. It has many small, individual transactions for everyday use.

BOTTLENECK: This category has relatively low overall spend and is not critical to the firm's operations. However, it is a unique category that is not easily available in the supply market supply continuity is important.

LEVERAGE: This category has fairly high overall spend and is critical to the business. It is readily available in the supply market, with many alternative products to choose from and ample inventories exist.

STRATEGIC: This category has fairly high overall spend and is critical to the firm's operations. There are only a few qualified suppliers for this category because of its unique and complex specifications. 
Figure 3: Example Hypothetical Situation of Supplier Selection ${ }^{\text {a }}$

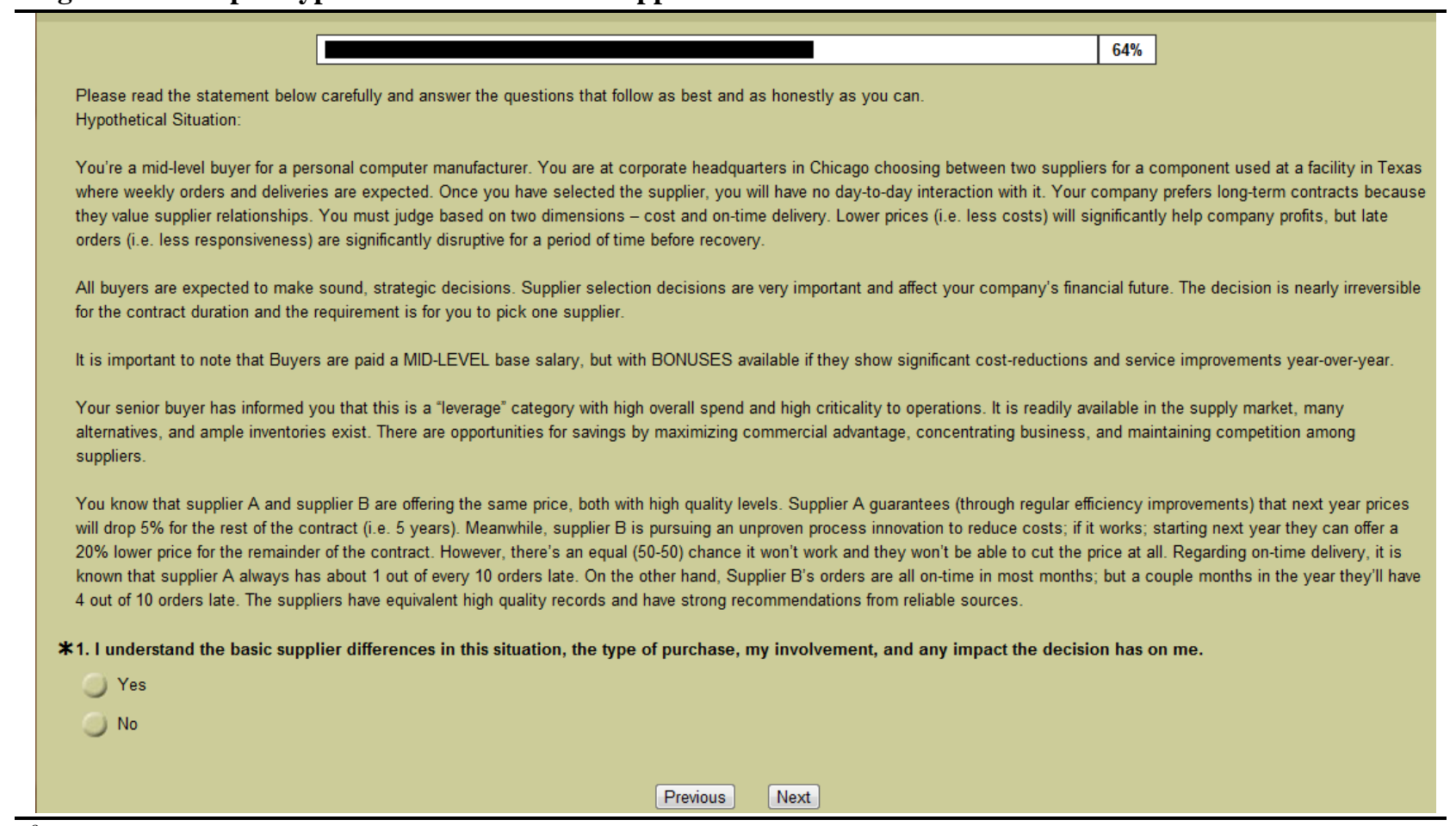

${ }^{\mathrm{a}}$ Web page example is Scenario 6 
Figure 4: Structural Equation Model Results

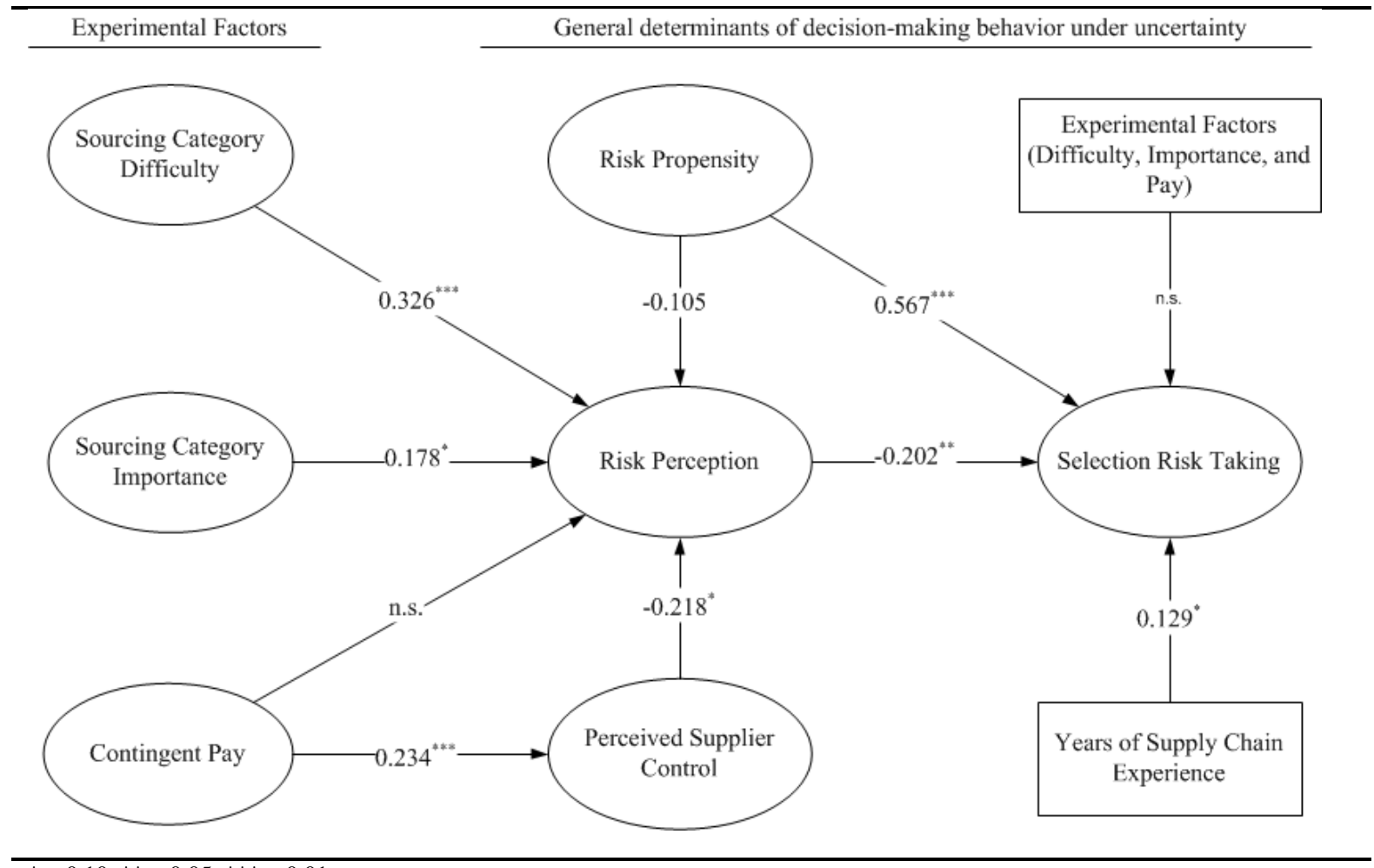

$* \mathrm{p}<0.10, * * \mathrm{p}<0.05, * * * \mathrm{p}<0.01$ 


\section{REFERENCES}

Amaral, J., \& Tsay, A. A. (2009). How to win "spend" and influence partners: Lessons in behavioral operations from the outsourcing game. Production and Operations Management, 18(6), 621-634.

Anderson, J. C., \& Gerbing, D. W. (1988). Structural equation modeling in practice: A review and recommended two-step approach. Psychological Bulletin, 103(3), 411-423.

Anderson, L. R., \& Mellor, J. M. (2009). Are risk preferences stable? Comparing an experimental measure with a validated survey-based measure. Journal of Risk and Uncertainty, 39(2), 137-160.

Bachrach, D. G., \& Bendoly, E. (2011). Rigor in behavioral experiments: A basic primer for supply chain management researchers. Journal of Supply Chain Management, 47(3), 5-8.

Bagozzi, R. P., \& Yi, Y. J. (1989). On the use of structural equation models in experimentaldesigns. Journal of Marketing Research, 26(3), 271-284.

Baird, I. S., \& Thomas, H. (1985). Toward a contingency model of strategic risk taking. Academy of Management. The Academy of Management Review, 10(2), 230.

Baird, I. S., \& Thomas, H. (1990). What is risk anyway? Using and measuring risk in strategic management. In R. A. Bettis, \& H. Thomas (Eds.), Risk, strategy, and management. Greenwich, CT: JAI Press, 21-52.

Beach, L. R., \& Mitchell, T. R. (1978). A contingency model for the selection of decision strategies. Academy of Management. The Academy of Management Review (pre-1986), 3(000003), 439-439.

Beatty, R. P., \& Zajac, E. J. (1994). Managerial incentives, monitoring, and risk bearing - a study of executive-compensation, ownership, and board structure in initial public offerings. Administrative Science Quarterly, 39(2), 313-335.

Bendoly, E. (2013). Real-time feedback and booking behavior in the hospitality industry: Moderating the balance between imperfect judgment and imperfect prescription. Journal of Operations Management, 31(1-2), 62-71.

Bendoly, E., Croson, R., Goncalves, P., \& Schultz, K. (2010a). Bodies of knowledge for research in behavioral operations. Production and Operations Management, 19(4), 434-452.

Bendoly, E., \& Eckerd, S. (2013). Behavioral om experiments: Critical inquiry reawakening practical issues in research. In I. Giannoccaro (Ed.), Behavioural issues in operations management: Trends in design, management, methodology: Springer - forthcoming.

Bendoly, E., Thomas, D., \& Capra, M. (2010b). Multilevel social dynamics considerations for project management decision makers: Antecedents and implications of group member tie development. Decision Sciences, 41(3), 459-490.

Bentler, P. M. (1995). Eqs structural equations program manual. Encino, CA: Multivariate Software, Inc.

Bettman, J. R. (1973). Perceived risk and its components - model and empirical test. Journal of Marketing Research, 10(2), 184-190.

Blais, A. R., \& Weber, E. U. (2006). A domain-specific risk-taking (dospert) scale for adult populations. Judgment and Decision Making Journal, 1(1), 33-47.

Bolt, M. A., Killough, L. N., \& Koh, H. C. (2001). Testing the interaction effects of task complexity in computer training using the social cognitive model. Decision Sciences, 32(1), 1-20.

Brockhaus, R. H. (1980). Risk-taking propensity of entrepreneurs. Academy of Management Journal, 23(3), 509-520. 
Busemeyer, J. R., \& Townsend, J. T. (1993). Decision field-theory - a dynamic cognitive approach to decision-making in an uncertain environment. Psychological Review, 100(3), 432-459.

Carter, C. R., Kaufmann, L., \& Michel, A. (2007). Behavioral supply management: A taxonomy of judgment and decision-making biases. International Journal of Physical Distribution \& Logistics Management, 37(8), 631-669.

Case, R. H., \& Scott, S. (1998). Fostering risk taking in research and development: The importance of a project's terminal value. Decision Sciences, 29(4), 765-783.

Catanach, A. H. J., \& Brody, R. G. (1993). Intangible assets, the loan portfolio and deposit mixes of stock savings \& loans. Accounting Horizons, 7(2), 12-12.

Choi, T. Y., \& Hartley, J. L. (1996). An exploration of supplier selection practices across the supply chain. Journal of Operations Management 14(4), 333-343.

Chopra, S., \& Sodhi, M. S. (2004). Managing risk to avoid supply-chain breakdown. MIT Sloan Management Review, 46(1), 53.

Chow, C. W., \& Haddad, K. M. (1991). Relative performance evaluation and risk-taking in delegated investment decisions. Decision Sciences, 22(3), 583-593.

Conchar, M. P., Zinkhan, G. M., Peters, C., \& Olavarrieta, S. (2004). An integrated framework for the conceptualization of consumers' perceived-risk processing. Journal of the Academy of Marketing Science, 32(4), 418-436.

Corman, S., \& Dooley, K. (2006). Crawdad text analysis software 2.0. Chandler, AZ: Crawdad Technologies.

Corman, S. R., Kuhn, T., McPhee, R. D., \& Dooley, K. J. (2002). Studying complex discursive systems - centering resonance analysis of communication. Human Communication Research, 28(2), 157-206.

Craighead, C. W., Blackhurst, J., Rungtusanatham, M. J., \& Handfield, R. B. (2007). The severity of supply chain disruptions: Design characteristics and mitigation capabilities. Decision Sciences, 38(1), 131-156.

Crook, T. R., \& Combs, J. G. (2007). Sources and consequences of bargaining power in supply chains. Journal of Operations Management, 25(2), 546-555.

Croson, R., Schultz, K., Siemsen, E., \& Yeo, M. L. (2013). Behavioral operations: The state of the field. Journal of Operations Management, 31(1-2), 1-5.

Dane, E., \& Pratt, M. G. (2007). Exploring intuition and its role in managerial decision making. Academy of Management. The Academy of Management Review, 32(1), 33-54.

Davis, F. D., \& Kottemann, J. E. (1994). User perceptions of decision-support effectiveness - 2 production planning experiments. Decision Sciences, 25(1), 57-78.

Dunford, B. B., Boswell, W. R., \& Boudreau, J. W. (2010). When do high-level managers believe they can influence the stock price? Antecedents of stock price expectancy cognitions. Human Resource Management, 49(1), 23-43.

Eisenhardt, K. M. (1989). Agency theory - an assessment and review. Academy of Management Review, 14(1), 57-74.

Ellis, S. C., Henry, R. M., \& Shockley, J. (2010). Buyer perceptions of supply disruption risk: A behavioral view and empirical assessment. Journal of Operations Management, 28(1), 34-46.

Fiegenbaum, A., \& Thomas, H. (2004). Strategic risk and competitive advantage: An integrative perspective. European Management Review, 1(1), 84-95. 
Forlani, D. (2002). Risk and rationality: The influence of decision domain and perceived outcome control on managers' high-risk decisions. Journal of Behavioral Decision Making, 15(2), 125-140.

Forlani, D., Parthasarathy, M., \& Keaveney, S. M. (2008). Managerial risk perceptions of international entry-mode strategies - the interaction effect of control and capability. International Marketing Review, 25(3), 292-311.

Fornell, C., \& Larcker, D. F. (1981). Evaluating structural equation models with unobservable variables and measurement error. Journal of Marketing Research, 18(1), 39-50.

Fox, C. R., \& Tversky, A. (1995). Ambiguity aversion and comparative ignorance. Quarterly Journal of Economics, 110(3), 585-603.

Fredendall, L., Hopkins, C., \& Bhonsle, A. (2005). Purchasing's internal service performance: Critical external and internal determinants. Journal of Supply Chain Management, 41(2), 26-38.

Ganzach, Y., Ellis, S., Pazy, A., \& Ricci-Siag, T. (2008). On the perception and operationalization of risk perception. Judgment and Decision Making Journal, 3(4), 317 324.

Ghosh, D. (1994). Tolerance for ambiguity, risk preference, and negotiator effectiveness. Decision Sciences, 25(2), 263-280.

Ghosh, D., \& Crain, T. L. (1993). Structure of uncertainty and decision-making - an experimental investigation. Decision Sciences, 24(4), 789-807.

Ghosh, D., \& Ray, M. R. (1992). Risk attitude, ambiguity intolerance and decision-making - an exploratory investigation. Decision Sciences, 23(2), 431-444.

Ghosh, D., \& Ray, M. R. (1997). Risk, ambiguity, and decision choice: Some additional evidence. Decision Sciences, 28(1), 81-104.

Gino, F., \& Pisano, G. (2008). Toward a theory of behavioral operations. Manufacturing Service Operations Management, 10(4), 676-691.

Goldfeld, C. (1999). Supplier strategies. West Palm Beach, FL: PT Publications.

Gould, J. E. (2001). Concise handbook of experimental methods for the behavioral and biological sciences. Boca Raton: CRC Press.

Grosz, B. J., Weinstein, S., \& Joshi, A. K. (1995). Centering - a framework for modeling the local coherence of discourse. Computational Linguistics, 21(2), 203-225.

Hair, J. F., Anderson, R. E., Tatham, R. L., \& Black, W. (1998). Multivariate data analysis (5th ed.): Prentice Hall.

Halpern-Felsher, B. L., Millstein, S. G., Ellen, J. M., Adler, N. E., Tschann, J. M., \& Biehl, M. (2001). The role of behavioral experience in judging risks. Health Psychology, 20(2), 120-126.

Harris, C. R., Jenkins, M., \& Glaser, D. (2006). Gender differences in risk assessment: Why do women take fewer risks than men? Judgment and Decision Making Journal, 1(1), 48-63.

Harvey, P., \& Victoravich, L. M. (2009). The influence of forward-looking antecedents, uncertainty, and anticipatory emotions on project escalation. Decision Sciences, 40(4), 759-782.

Hawes, J. M., \& Barnhouse, S. H. (1987). How purchasing agents handle personal risk. Industrial Marketing Management, 16(4), 287-293.

Ho, W., Xu, X., \& Dey, P. K. (2010). Multi-criteria decision making approaches for supplier evaluation and selection: A literature review. European Journal of Operational Research, 202(1), 16-24. 
Houghton, S. M., Simon, M., Aquino, K., \& Goldberg, C. B. (2000). No safety in numbers persistence of biases and their effects on team risk perception and team decision making. Group \& Organization Management, 25(4), 325-353.

Hult, G. T. M., Craighead, C. W., \& Ketchen, D. J. (2010). Risk uncertainty and supply chain decisions: A real options perspective. Decision Sciences, 41(3), 435-458.

Hunton, J. E. (1996). Involving information system users in defining system requirements: The influence of procedural justice perceptions on user attitudes and performance. Decision Sciences, 27(4), 647-647.

Kathuria, R., Murugan, A., \& Magid, I. (1999). Linking it applications with manufacturing strategy: An intelligent decision support system approach. Decision Sciences, 30(4), 959991.

Keil, M., Depledge, G., \& Rai, A. (2007). Escalation: The role of problem recognition and cognitive bias. Decision Sciences, 38(3), 391-421.

Klos, A. (2005). Investment decisions and time horizon: Risk perception and risk behavior in repeated gambles. Management Science, 51(12), 1777-1790.

Kocabasoglu, C., Prahinski, C., \& Klassen, R. D. (2007). Linking forward and reverse supply chain investments: The role of business uncertainty. Journal of Operations Management, 25(6), 1141-1160.

Kraljic, P. (1983). Purchasing must become supply management,. Harvard Business Review, 61(5, ), 109-117.

Krueger, N., \& Dickson, P. R. (1994). How believing in ourselves increases risk-taking perceived self-efficacy and opportunity recognition. Decision Sciences, 25(3), 385-400.

Kuhberger, A. (1998). The influence of framing on risky decisions: A meta-analysis. Organizational Behavior and Human Decision Processes, 75(1), 23-55.

Kull, T. J., \& Talluri, S. (2008). A supply risk reduction model using integrated multicriteria decision making. Ieee Transactions on Engineering Management, 55(3), 409-419.

Langer, E. J. (1975). Illusion of control. Journal of Personality and Social Psychology, 32(2), 311-328.

Larraza-Kintana, M., Wiseman, R. M., Gomez-Mejia, L. R., \& Welbourne, T. M. (2007). Disentangling compensation and employment risks using the behavioral agency model. Strategic Management Journal, 28(10), 1001-1019.

Lee, D. Y. (1997). The impact of poor performance on risk-taking attitudes: A longitudinal study with a pls causal modeling approach. Decision Sciences, 28(1), 59-80.

Levin, I. P., Schneider, S. L., \& Gaeth, G. J. (1998). All frames are not created equal: A typology and critical analysis of framing effects. Organizational Behavior and Human Decision Processes, 76(2), 149-188.

Lipshitz, R., \& Strauss, O. (1997). Coping with uncertainty: A naturalistic decision-making analysis. Organizational Behavior and Human Decision Processes, 69(2), 149-163.

Luce, M. F., Payne, J. W., \& Bettman, J. R. (1999). Emotional trade-off difficulty and choice. Journal of Marketing Research, 36(2), 143-159.

MacCrimmon, K. R., \& Wehrung, D. A. (1990). Characteristics of risk taking executives. Management Science, 36(4), 422.

March, J. G., \& Shapira, Z. (1987). Managerial perspectives on risk and risk taking. Management Science, 33(11), 1404.

Martin, D. W. (2004). Doing psychology experiments (Sixth ed.). Belmont, CA: Wadsworth. 
McCutcheon, D., \& Stuart, F. I. (2000). Issues in the choice of supplier alliance partners. Journal of Operations Management, 18(3), 279-301.

McQuiston, D. H. (1989). Novelty, complexity, and importance as causal determinants of industrial buyer behavior. Journal of Marketing, 53(2), 66-79.

Miller, K. D., \& Chen, W. R. (2004). Variable organizational risk preferences: Tests of the march-shapira model. Academy of Management Journal, 47(1), 105-115.

Min, H. (1994). International supplier selection: A multi-attribute utility approach. International Journal of Physical Distribution \& Logistics Management, 24(5), 24.

Mitchell, V.-W. (1995). Organizational risk perception and reduction: A literature review. British Journal of Management, 6(2), 115-115.

Mittal, V., \& Ross, W. T. (1998). The impact of positive and negative affect and issue framing on issue interpretation and risk taking. Organizational Behavior and Human Decision Processes, 76(3), 298-324.

Monczka, R. M., Handfield, R. B., Giunipero, L. C., \& Patterson, J. L. (2009). Purchasing and suppy chain management (4th ed.). Mason, $\mathrm{OH}$ : South-Western.

Narasimhan, R., \& Talluri, S. (2009). Perspectives on risk management in supply chains. Journal of Operations Management, 27(2), 114.

Narasimhan, R., Talluri, S., \& Mahapatra, S. K. (2006). Multiproduct, multicriteria model for supplier selection with product life-cycle considerations. Decision Sciences, 37(4), 577603.

Neige, D., Rotaru, K., \& Churilov, L. (2009). Supply chain risk identification with value-focused process engineering. Journal of Operations Management, 27(2), 154.

Nicholson, N. (2005). Personality and domain-specific risk taking. Journal of Risk Research, 8(2), 157-176.

Olsen, R. F., \& Ellram, L. M. (1997). A portfolio approach to supplier relationships. Industrial Marketing Management, 26(2), 101-113.

Pennings, J. M. E., \& Wansink, B. (2004). Channel contract behavior: The role of risk attitudes, risk perceptions, and channel members' market structures. Journal of Business, 77(4), 697-723.

Perdue, B. C., \& Summers, J. O. (1986). Checking the success of manipulations in marketing experiments. Journal of Marketing Research, 23(4), 317-326.

Pitz, G. F. (1992). Risk taking, design, and training. In J. F. Yates (Ed.), Risk-taking behavior. New York: Wiley, 3-25.

Podsakoff, P. M., MacKenzie, S. B., Lee, J. Y., \& Podsakoff, N. P. (2003). Common method biases in behavioral research: A critical review of the literature and recommended remedies. Journal of Applied Psychology, 88(5), 879-903.

Presson, P. K., \& Benassi, V. A. (1996). Illusion of control: A meta-analytic review. Journal of Social Behavior and Personality, 11(3), 493-510.

Puto, C. P. (1987). The framing of buying decisions. Journal of Consumer Research, 14(3), 301315.

Raju, P. S. (1980). Optimum stimulation level - its relationship to personality, demographics, and exploratory-behavior. Journal of Consumer Research, 7(3), 272-282.

Riedl, D. F., Kaufmann, L., Zimmermann, C., \& Perols, J. L. (2013). Reducing uncertainty in supplier selection decisions: Antecedents and outcomes of procedural rationality. Journal of Operations Management, 31(1-2), 24-36. 
Rossetti, C., \& Choi, T. Y. (2005). On the dark side of strategic sourcing: Experiences from the aerospace industry. Academy of Management Executive, 19(1), 46-60.

Rubinstein, A. (1998). Modeling bounded rationality. Cambridge, Mass: MIT Press.

Rubinstein, A. (2012). Economic fables: Open book publishers.

Rungtusanatham, M., Wallin, C., \& Eckerd, S. (2011). The vignette in a scenario-based roleplaying experiment. Journal of Supply Chain Management, 47(3), 9-16.

Saini, A., \& Martin, K. D. (2009). Strategic risk-taking propensity: The role of ethical climate and marketing output control. Journal of Business Ethics, 90(4), 593-606.

Schoemaker, P. J. H. (1982). The expected utility model - its variants, purposes, evidence and limitations. Journal of Economic Literature, 20(2), 529-563.

Shadish, W. R., Cook, T. D., \& Campbell, D. T. (2002). Experimental and quasi-experimental designs for generalized causal inference. Boston: Houghton Mifflin.

Shapira, Z. (1995). Risk taking: A managerial perspective. New York: Russel Sage Foundation.

Simon, M., Houghton, S. M., \& Aquino, K. (2000). Cognitive, biases, risk perception and venture formation: How individuals decide to start companies. Journal of Business Venturing, 15(2), 113-134.

Sitkin, S. B., \& Pablo, A. L. (1992). Reconceptualizing the determinants of risk behavior. Academy of Management Review, 17(1), 9-38.

Sitkin, S. B., \& Weingart, L. R. (1995). Determinants of risky decision-making behavior: A test of the mediating role of risk perceptions and propensity. Academy of Management Journal, 38(6), 1573-1592.

Slovic, P. (1987). Perceptions of risk. Science, 236(4799), 280-285

Stewart, W. H., \& Roth, P. L. (2001). Risk propensity differences between entrepreneurs and managers: A meta-analytic review. Journal of Applied Psychology, 86(1), 145-153.

Talluri, S., Narasimhan, R., \& Nair, A. (2006). Vendor performance with supply risk: A chanceconstrained dea approach. International Journal of Production Economics, 100(2), 212222.

Tangpong, C., Hung, K. T., \& Ro, Y. K. (2010). The interaction effect of relational norms and agent cooperativeness on opportunism in buyer-supplier relationships. Journal of Operations Management, 28(5), 398-414.

Tazelaar, F., \& Snijders, C. (2013). Operational risk assessments by supply chain professionals: Process and performance. Journal of Operations Management, 31(1-2), 37-51.

Tiwana, A., Wang, J. J., Keil, M., \& Ahluwalia, P. (2007). The bounded rationality bias in managerial valuation of real options: Theory and evidence from it projects. Decision Sciences, 38(1), 157-181.

Tomlin, B. (2006). On the value of mitigation and contingency strategies for managing supply chain disruption risks. Management Science, 52(5), 639-657.

Treleven, M., \& Schweikhart, S. B. (1988). A risk/benefit analysis of sourcing strategies: Single vs. Multiple sourcing. Journal of Operations Management, 7(3,4), 93.

Villena, V. H., Gomez-Mejia, L. R., \& Revilla, E. (2009). The decision of the supply chain executive to support or impede supply chain integration: A multidisciplinary behavioral agency perspective*. Decision Sciences, 40(4), 635-665.

Wang, W. Q., \& Benbasat, I. (2008). Attributions of trust in decision support technologies: A study of recommendation agents for e-commerce. Journal of Management Information Systems, 24(4), 249-273. 
Weber, C. A., Current, J. R., \& Benton, W. C. (1991). Vendor selection criteria and methods. European Journal of Operational Research, 50(1), 2.

Webster, F. E., \& Wind, Y. (1972). General model for understanding organizational buying behavior. Journal of Marketing, 36(2), 12-19.

Wiseman, R. M., \& Gomez-Mejia, L. R. (1998). A behavioral agency model of managerial risk taking. Academy of Management Review, 23(1), 133-153.

Wouters, M., Anderson, J. C., Narus, J. A., \& Wynstra, F. (2009). Improving sourcing decisions in npd projects: Monetary quantification of points of difference. Journal of Operations Management, 27(1), 64.

Yates, J. F., \& Stone, E. R. (1992). The risk construct. In J. F. Yates (Ed.), Risk-taking behavior. New York: Wiley, 3-25.

Zsidisin, G. A. (2003). Managerial perceptions of supply risk. Journal of Supply Chain Management, 38(1), 14-25.

Zsidisin, G. A., \& Ellram, L. M. (2003). An agency theory investigation of supply risk management. Journal of Supply Chain Management, 39(3), 15.

Zsidisin, G. A., \& Wagner, S. M. (2010). Do perceptions become reality? The moderating role of supply chain resiliency on disruption occurrence. Journal of Business Logistics, 31(2), 120. 